\title{
Disentangling the Forcing Mechanisms of a Heavy Precipitation Event along the Alpine South Side Using Potential Vorticity Inversion
}

\author{
Linda Schlemmer, Olivia Martius, And Michael Sprenger \\ Institute for Atmospheric and Climate Science, ETH Zurich, Zurich, Switzerland \\ CORNELIA SCHWIERZ \\ Seminar für Statistik, ETH Zurich, Zurich, Switzerland \\ ARWEN TWITCHETT \\ Institute for Climate and Atmospheric Science, School of Earth and Environment, \\ University of Leeds, Leeds, United Kingdom
}

(Manuscript received 25 August 2009, in final form 9 December 2009)

\begin{abstract}
Extreme precipitation events along the Alpine south side (AS) are often forced by upper-level positive potential vorticity (PV) anomalies over western Europe. These so-called PV streamers go along with a dynamical forcing for upward motion, a reduction of the static stability in the troposphere (hence facilitating convection), and are associated with low-level winds that transport moisture toward the Alps.

A case of heavy precipitation is examined using the 40-yr ECMWF Re-Analysis data. Piecewise PV inversion (PPVI) and the limited-area Climate High Resolution Model (CHRM) are used to assess the influences of mesoscale parts of the streamer on the precipitation event. The impacts on the vertical stability are quantified by the convective available potential energy (CAPE) and an index of static stability. Very sensitive areas in terms of the stability are located beneath the southern tip of the streamer; smaller changes in the stability are observed in the Alpine region.

The moisture transport toward the Alps is sensitive to the amplitude of the streamer, which influences the amount of water that can be transported along its eastern flank.

The impacts of the topography on the flow are assessed by calculating an average inverse Froude number. Whether or not the air parcels are blocked by or lifted over the barrier (going along with suppressed and enhanced precipitation, respectively) depends on the vertical stability and the impinging wind velocity, two parameters that are inherently linked to the PV streamer and its substructure.
\end{abstract}

\section{Introduction}

Heavy precipitation (HP) events occurring in highly structured and steep terrain (here the southern flanks of the European Alps) often cause secondary natural hazards (e.g., flooding, landslides) that represent serious threats to the population and infrastructure. This study focuses on improving our understanding of synopticand mesoscale atmospheric mechanisms causing such events. As a long-term objective, it aims to advance the

Corresponding author address: Linda Schlemmer, Institute for Atmospheric and Climate Science, ETH Zurich, 8092 Zurich, Switzerland.

E-mail: linda.schlemmer@env.ethz.ch prediction of the location and intensity of similar HP events.

Recognizing the importance of the topic, the Mesoscale Alpine Programme (MAP) (e.g., Bougeault et al. 2001) focused on the factors influencing precipitation in the complex topography of the Alpine region. Both mesoscale and large-scale flow dynamics impact the precipitation intensity and its spatial structure. On the mesoscale, the flow strongly interacts with the local topography (Gheusi and Davies 2004) and thus triggers convection (e.g., Buzzi et al. 1998; Fuhrer and Schär 2005). On the synoptic-scale, high potential vorticity (PV) intrusions over western Europe play an important role in forcing HP along the Alpine south side (Massacand et al. 1998, 2001; Martius et al. 2006; Hoinka and Davies 
2007). Generally, these intrusions adopt the form of narrow $(\sim 500 \mathrm{~km})$, deep $(\sim 4 \mathrm{~km})$, and meridionally elongated $(\sim 2000 \mathrm{~km})$ filaments of stratospheric air, termed PV streamers (Appenzeller and Davies 1992), and reach from the British Isles southward to the Iberian Peninsula. These PV structures are reflected in geopotential troughs located over western Europe (e.g., Jacobeit 1987; Rudari et al. 2005).

A PV streamer, being a positive upper-level PV anomaly, has several dynamical characteristics that can trigger and/or enhance precipitation:

(a) The static stability in the troposphere is reduced underneath a streamer (Hoskins et al. 1985) and the initiation of convection is thus facilitated.

(b) In a Lagrangian sense, air is forced to ascend northward along the PV streamer's downstream flank, following the sloping isentropes (e.g., Hoskins et al. 1985). From an Eulerian perspective the horizontal movement of the streamer leads to a lifting of isentropes as it passes by (the so-called vacuum cleaner effect). The induced vertical motion can initiate additional convection along the downstream flank of the streamer (e.g., Funatsu and Waugh 2008).

(c) The flow induced by an elongated streamer over western Europe can penetrate to the ground and transport moisture from the Atlantic and/or the Mediterranean Sea toward the Alps (e.g., Reale et al. 2001; Koch 2004; Turato et al. 2004). The strong southerly flow along the eastern flank of the PV streamer can act like a conveyor belt and bring large amounts of moisture toward the Alps. This phenomenon is known as a warm conveyor belt (Eckhardt et al. 2004) or as atmospheric rivers (Newell et al. 1992) in other parts of the world.

(d) In the particular setting of the streamer being located over western Europe, the Alps act as an additional forcing factor. The streamer influences both the low-level wind field and the static stability and therefore has a crucial impact on the way the flow interacts with the orography, with major implications for the location and intensity of the precipitation. Further on, the orography slows down the eastward progression of the streamer (Morgenstern and Davies 1999). Both factors have a crucial impact on the overall amount of precipitation, which is determined by the duration of an event multiplied by its rainfall rate (Doswell et al. 1996).

The mesoscale parts of the streamer influence points a, c, and d listed above. Indeed, Fehlmann et al. (2000) show that the location, extension, and effective amplitude of mesoscale PV substructures substantially influence precipitation patterns on the Alpine south side
(AS). This study builds upon and extends their work by quantifying the effects of the substructure of the streamer on forcing factors a, c, and d, and by addressing their relevance for one specific precipitation event.

The correct representation of the mesoscale substructure of a streamer still poses a challenge to state-ofthe-art weather prediction models. As demonstrated in Fehlmann and Quadri (2000), these mesoscale substructures are relevant for the forecast quality. They find that forecasts of HP along the Alpine south side are sensitive to the location and amplitude of the southern part of the streamer. Grazzini (2007) found that the skill in predicting the strong moisture fluxes associated with HP events has improved at a faster rate than the skill for average conditions since 1986. Nevertheless, errors in the forecasted PV field in amplitude, phase, and substructure still occur in present-day forecasts (e.g., Dirren et al. 2003; Didone 2006).

This study focuses on one HP event that occurred on 13 November 1996 and it addresses the following questions concerning the factors favoring HP: What is the PV streamer's dynamical role in the tropospheric destabilization? How does the mesoscale substructure influence the northward advection of water vapor? Finally, to what degree does it influence the orographic lifting and enhancement of convection? To answer these questions, we modify the streamer's substructure using piecewise PV inversion (PPVI) (Davis 1992). The design of the experiments is guided by an analysis of the typical structure and amplitude of forecast errors for streamer -induced HP events.

The paper is organized the following way. A detailed description of the PPVI method and the data used is given in section 2. An overview over the synoptic situation, as well as a short discussion of typical forecast errors, are presented in section 3 , followed by an indepth discussion of the PPVI application to the mesoscale substructure of the PV streamer (section 4) and implications for the precipitation (section 5). Finally, the main results are summarized in section 6 .

\section{Data and methodology}

a. Data

The meteorological fields used in the case study stem from the 40-yr European Centre for Medium-Range Weather Forecasts (ECMWF) Re-Analysis (ERA-40) dataset (Uppala et al. 2005) and are interpolated onto a $1^{\circ} \times 1^{\circ}$ latitude-longitude grid. The verification fields for the precipitation are taken from an observation-based Alpine precipitation climatology (Frei and Schär 1998). Finally, for the assessment of the forecast errors, we use ECMWF operational forecast and analysis data. 
TABLE 1. Parameters used to define the filtering box for the PV anomaly. The center of rotation is given in latitude and longitude as well as the angle by which the box is rotated. The extent of the box in the Cartesian grid is given by the maximum and minimum values for the $x$ and $y$ directions in $\mathrm{km}$.

\begin{tabular}{lccccccc}
\hline \hline Modification & $\begin{array}{c}\text { Lat } \\
\left(^{\circ}\right)\end{array}$ & $\begin{array}{c}\text { Lon } \\
\left(^{\circ}\right)\end{array}$ & $\begin{array}{c}\text { Angle } \\
\left(^{\circ}\right)\end{array}$ & $\begin{array}{c}x_{\min } \\
(\mathrm{km})\end{array}$ & $\begin{array}{c}x_{\max } \\
(\mathrm{km})\end{array}$ & $\begin{array}{c}y_{\min } \\
(\mathrm{km})\end{array}$ & $\begin{array}{c}y_{\max } \\
(\mathrm{km})\end{array}$ \\
\hline $\begin{array}{l}\text { TR } \\
\text { TA }\end{array}$ & 38 & -15 & 5 & -1000 & 1500 & -700 & 500 \\
$\begin{array}{l}\text { ER } \\
\text { EA }\end{array}$ & 47 & 0 & 35 & -500 & 800 & -2200 & 1500 \\
SB & 47 & -10 & 30 & -800 & 1200 & -1800 & 1800 \\
\hline
\end{tabular}

\section{b. Piecewise PV inversion and model runs}

The PPVI technique used for this study was originally developed by Fehlmann (1997) and the approach slightly differs from that of Davis (1992). In a nutshell, this PPVI approach is based upon the quasigeostrophic approximation, but takes into account the nonlinearity of the Ertel-PV inversion problem by using an iterative technique. For further details, refer to Fehlmann (1997).

The first step in the inversion is the definition of a PV anomaly, which is done using a simple spatial-filtering technique. A three-dimensional box is placed around the PV structure to be modified. Within this box the PV is smoothed by building the zonal mean within the box. The filtered field is then subtracted from the original field. The size and the amplitude of the PV anomaly are dependent on the size of the box and the number of iterations of the filter. The location and size of the box used for each experiment are listed in Table 1. In the vertical, the box extends from $2 \mathrm{~km}$ up to $15 \mathrm{~km}$. Five iterations of the filter were done. This approach allows us to modify mesoscale substructures within a synopticscale PV anomaly. The resulting anomaly is separated into its positive and negative parts and the positive part is the PV anomaly to be inverted. Boundary values for potential temperature (upper and lower lids) and horizontal wind (lateral boundaries) are set to zero. With this choice of boundary conditions an ambiguity is introduced (Hakim et al. 1996) because multiple states can share the same PV distribution. Hence, the new balanced state is a realistic and a correct solution of the inversion problem, but it is not necessarily a unique solution. Finally, we developed a simple algorithm that allows us to modify the form and amplitude of a PV anomaly. Using this tool, the anomaly is scaled to its desired form and added to the background field.

After the PPVI, the inverted fields undergo an implicit normal mode initialization (Temperton 1988; Temperton and Roch 1991). This step removes spurious fast-moving gravity waves, which can arise from the PPVI.
The output of the PPVI serves as initial condition for numerical weather prediction (NWP) simulations. We use the Climate High Resolution Model (CHRM), which is a modification of version 1.6 of the High Resolution Model (HRM) of the German Weather Service (for more details, see Majewski 1999; Lüthi et al. 1996; Vidale et al. 2003). The hydrostatic model is run with 40 vertical levels, and the variables are interpolated onto a latitude-longitude grid with $0.5^{\circ} \times 0.5^{\circ}$ horizontal resolution. The parameterized physical processes include a vertical diffusion scheme of order 1.5, after Mellor and Yamada (1974), and a surface-layer formulation, after Holtslag and Boville (1993); Kessler-type grid-scale microphysics (Kessler 1969), including a parameterization of the ice-phase (Lin et al. 1983); and a mass flux convection scheme, after Tiedtke (1989). Initial fields are taken from the ERA-40 data for the control run and from the corresponding output of the PPVI experiments. Boundary conditions are taken from the ERA-40 data. The model is integrated for $24 \mathrm{~h}$.

\section{c. Moisture treatment}

The humidity field remains unchanged during the PPVI procedure. This leads to discrepancies between the unchanged moisture and the modified wind and temperature fields. First, the temperature can fall below the calculated dewpoint temperature at some grid points and the PPVI hence leads to artificial supersaturation (thermodynamic inconsistency). Second, the moisture distribution is determined by the wind and temperature fields associated with the original PV distribution. If the latter is altered, with associated changes in temperature and wind, the unchanged moisture is hence no longer dynamically consistent with the flow (flow evolution inconsistency). This is of particular importance if the PV alterations are carried out in the tropics and if the inverted fields are used to initialize model runs (McTaggart-Cowan et al. 2003).

We present three approaches to address these problems by adapting the moisture distribution after the PPVI. In a first approach (QI), the moisture field is corrected to $100 \%$ relative humidity at points where oversaturation occurs and the specific humidity is kept constant elsewhere. In a second approach ( $\mathrm{RH})$, the relative humidity is kept constant. In a third, more radical approach, the humidity field is filtered on constant height surfaces inside the inversion domain (FI). In this approach we apply five iterations of a median filter of size $10 \times 15$ grid points onto the humidity field. The filter conserves the planetaryscale structure of the moisture field, but the synoptic-scale structures are removed. This third approach is closest to the solution chosen by Funatsu and Waugh (2008), who use a climatological moisture distribution. 
Finally, note that we apply only mesoscale changes to the original PV field and that the integration time of the NWP model is short $(24 \mathrm{~h})$. Under the assumption of approximate linearity, this leads to correspondingly small changes in the temperature and humidity fields.

\section{d. Stability and flow-regime diagnostics}

The convective potential is assessed by means of mostunstable convective available potential energy (CAPE) and convective inhibition (CIN) (see, e.g., Emanuel 1994). CAPE and CIN are calculated using the postprocessing routine of the Consortium for Small-scale Modeling (COSMO; Steppeler et al. 2003) adjusted for ECMWF fields. A classical parcel ascent is calculated for the most-unstable parcel in the lowest $300 \mathrm{hPa}$. In addition, the static stability is assessed using four traditional indices and combining them into a new combined threshold index (CTI): the totals index (Miller 1972), the $K$ index (George 1960), and the squared dry and wet BruntVäisälä frequencies at $850 \mathrm{hPa}$. The dry Brunt-Väisälä frequency $N$ was calculated using $N=\sqrt{(g / \theta)(\partial \theta / \partial z)}$, with the wet one $N_{w}$ accordingly using the equivalent potential temperature $\theta_{e}$ instead of the potential temperature $\theta$. Here, $\theta_{e}$ was determined using the formula developed by Bolton (1980). These four indices are combined into a new index in the following way. For each individual index, a threshold is set that divides stable from unstable stratification. The combined index is then simply the number of individual indices that surpass their instability threshold; hence, it varies between 0 (stable) and 4 (unstable). The following thresholds are used: totals index $>44 \mathrm{~K}, K$ index $<24 \mathrm{~K}$, squared dry Brunt-Väisälä frequency at $850 \mathrm{hPa}<10^{-4} \mathrm{~s}^{-2}$, and squared wet Brunt-Väisälä frequency $<0 \mathrm{~s}^{-2}$. In contrast to $N, N_{w}$ exceeds the set threshold for particularly wet regions located primarily in the Atlantic and the Mediterranean. The $K$ index and the totals index are not independent since they both evaluate temperature and dewpoint at the same levels. However, in many cases the two thresholds are exceeded at different locations. A similar procedure has been used to identify unstable regions from satellite images (see, e.g., Mecikalski and Bedka 2006).

The vertical stability, the speed of the incident flow, and the shape and height of the topography determine whether the air impinging upon the Alps is blocked by the latter or carried over it. The inverse Froude number (or dimensionless mountain height), $\epsilon=N H_{0} / U$ (where $H_{0}$ is the mountain height and $U$ the incident flow speed), is a widely used measure for distinguishing between the two flow configurations or for deciding which part of the impinging flow is blocked and which is able to surpass the Alpine barrier.
Studies determining the flow response have mainly focused on idealized flow over idealized topography (e.g., Schär and Davies 1988; Smith 1989; Ólafsson and Bougeault 1997). Reinecke and Durran (2008) investigated different methods to characterize nonuniform flows using the inverse Froude number. We follow their approach and calculate the inverse Froude number based on the bulk value $N=\sqrt{\left(g / \theta_{00}\right)\left(\theta_{H_{0}}-\theta_{00}\right) / H_{0}}$ where $\theta_{00}$ is the reference potential temperature at the ground and $\theta_{H_{0}}$ the potential temperature at $H_{0}$. Following Reinecke and Durran (2008), the bulk method is the better predictor of the low-level flow diversion. The $U$ and $N$ values are evaluated along a cross section across the Alps, parallel to the wind field at $850 \mathrm{hPa}$. Here, $H_{0}$ is set to $2000 \mathrm{~m}$, and $U$ at $H_{0}$ as well as $N$ are identified one Rossby radius of deformation $L_{R}=N_{0}$ / $f_{0} \approx 90 \mathrm{~km}$ away from the barrier (Pierrehumbert and Wyman 1985). The exact distance of the identification point from the Alps is not very critical because the wind and stability are relatively uniform for grid points farther than approximately $80 \mathrm{~km}$ away from the Alps. Typically, the transition from blocked to cross-mountain flow occurs at $\epsilon_{\text {crit }}=1.0-1.2$.

\section{Synoptic overview and forecast error assessment}

\section{a. Synoptic situation}

A deep trough in the 500-hPa geopotential was located over the eastern Atlantic and western Europe on 13 November 1996 (not shown). This trough went along with a meridionally elongated pattern of high PV (a PV streamer) located over western Europe, which extended south to $\approx 32^{\circ} \mathrm{N}$ (Fig. 1). It will be shown that this synopticscale PV streamer acted as the main upper-level forcing of the precipitation. The streamer formed on 11 November 1996, became progressively longer and thinner, and reached its maximal elongation on 13 November. At this time, the dynamical tropopause was considerably lowered. The minimum height of the 2-PVU isosurface was found at $550 \mathrm{hPa}$ over northern Germany at 1800 UTC 13 November 1996 (not shown).

An elongated mesoscale structure of high-PV air ( $>8$ PVU), located inside the synoptic-scale PV streamer, moved northward along the eastern flank of the streamer between 1800 UTC 11 November and 1800 UTC 12 November. This structure was linked to a local upperlevel wind maximum that had a considerable PV crossgradient component, which lead to PV advection and influenced the temporal evolution of the streamer (not shown). The streamer followed a typical anticyclonic life cycle. At 0600 UTC 13 November, a hook-like structure formed at the tip of the streamer, indicating 

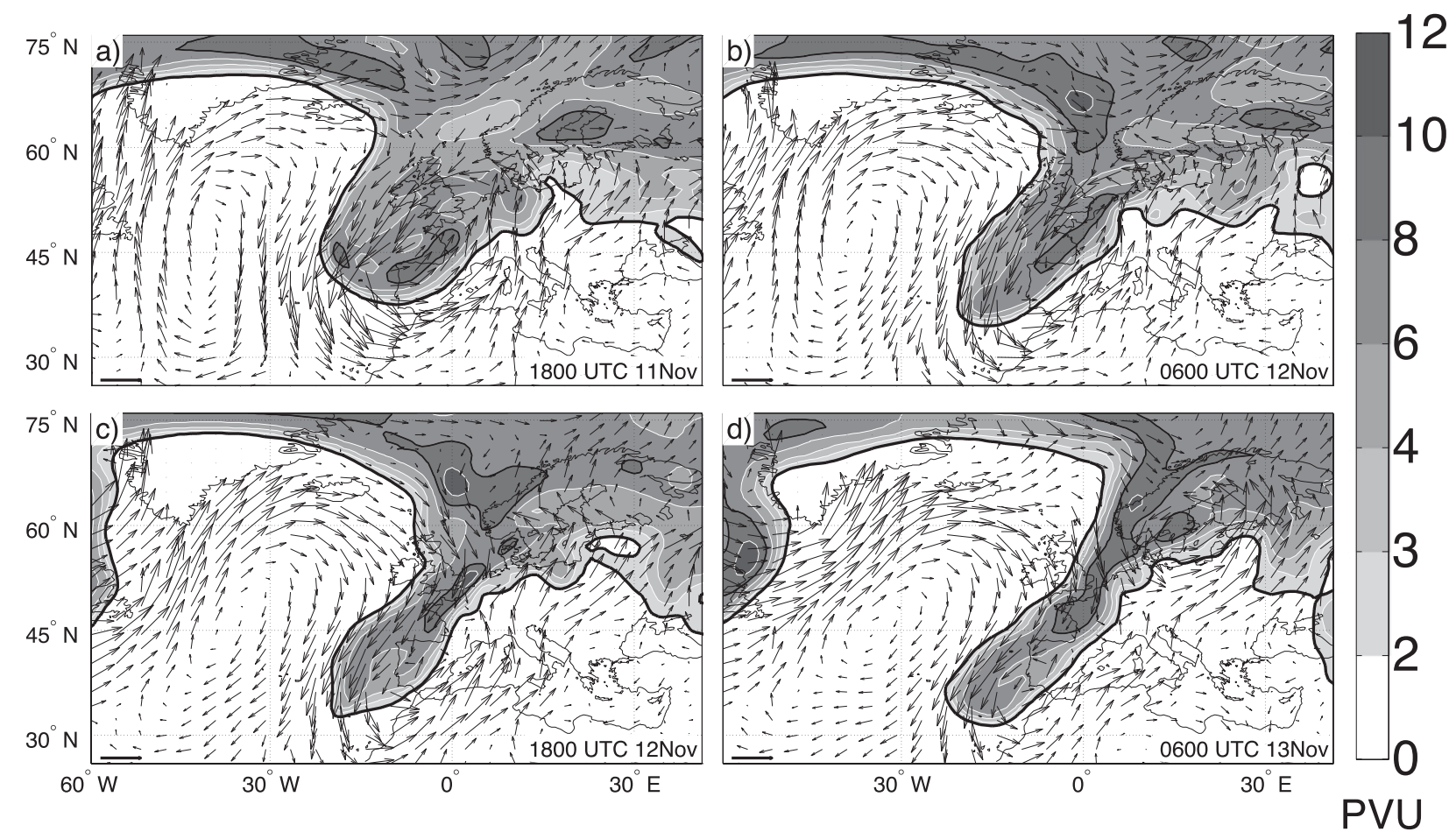

FIG. 1. Evolution of the PV at $320 \mathrm{~K}$ (shaded) in the ERA-40 dataset. The bold black line indicates the 2-PVU isoline; the thin black line the 8-PVU isoline. The following dates are shown: (a) 1800 UTC 11 Nov, (b) 0600 UTC 12 Nov, (c) 1800 UTC 12 Nov, and (d) 0600 UTC 13 Nov 1996. The arrows represent the wind field at $850 \mathrm{hPa}$. The horizontal line in the lower-left corner corresponds to a wind speed of $20 \mathrm{~m} \mathrm{~s}^{-1}$.

local cyclonic wrapping and the beginning of barotropic decay.

A strong wind field was coaligned with the rim of the streamer and extended all the way through the troposphere. The low-level wind maximum along the eastern flank was associated with a band-like structure of very humid air that extended northward from the subtropics toward the Alps prior to the onset of and during the HP period (Fig. 2a). The precipitation accumulated between 0600 UTC November 12 and 0600 UTC 13 November 1996 is shown in Fig. 3. The 24-h accumulated precipitation exceeded $120 \mathrm{~mm}$ in the French Alps (label A), $25 \mathrm{~mm}$ in the Piedmont (label B), and $100 \mathrm{~mm}$ in southern Switzerland (label C).

The midtropospheric isentropes exhibit the characteristic displacement in the vertical associated with a positive upper-level PV streamer (see, e.g., Funatsu and Waugh 2008, Fig. 3; Hoskins et al. 1985). They slope upward both toward the center of the anomaly in the east-west direction and toward the north in the northsouth direction (not shown). The changes in the vertical temperature structure are reflected in the dry stability. This can be seen in a vertical cross section through the tip region showing $N^{2}$ (Fig. 4a). Stratospheric air intrudes into the troposphere and the isentropes are bent upward underneath the streamer, indicating a cold anomaly in the lower troposphere. A "bubble" of reduced stability ( small $N^{2}$ ) is located directly underneath the streamer (between 380 and $600 \mathrm{hPa}$ and $15^{\circ}$ and $10^{\circ} \mathrm{W}$, label A). Below, a stable layer separates the bubble from the unstable surface layer between $850 \mathrm{hPa}$ and the ground. A band of relatively high stability extending from the surface up to the tropopause is located to the west of the streamer (see Fig. 4a, label B). This band is closely linked to the upper-level intrusion and the associated lifting of the isentropes. The high spatial variability of the stability pattern is illustrated further in a plan view of $N^{2}$ at $450 \mathrm{hPa}$ (Fig. 4b). Areas of low stability are found underneath the center part of the streamer (where we observe the bubble in Fig. 4a) and a band of high stability is located along the streamer's western edge.

The observed distribution of CAPE is closely tied to the upper-level PV field and is characterized by high values (up to $930 \mathrm{~J} \mathrm{~kg}^{-1}$ ) in the tip region of the streamer (Fig. 5a). The tip is situated over the ocean where the lower troposphere is moist and hence favors convection. Values of up to $300 \mathrm{~J} \mathrm{~kg}^{-1}$ are found over the French 

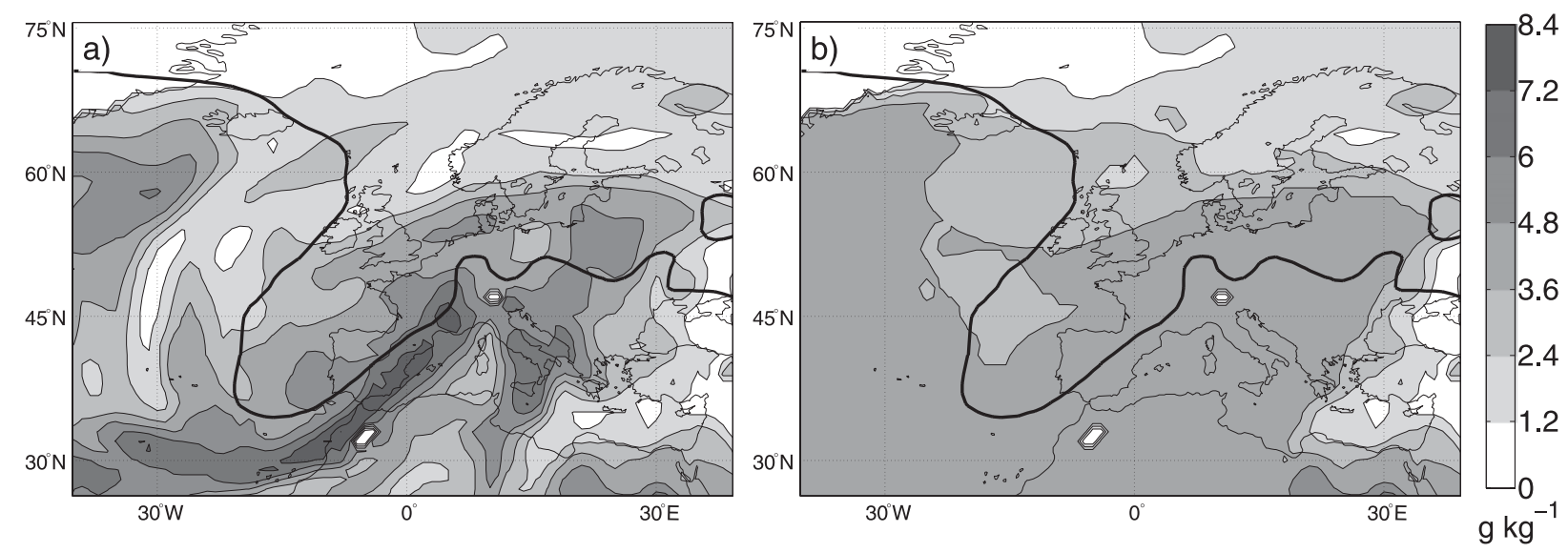

FIG. 2. Specific humidity (shaded; $\mathrm{g} \mathrm{kg}^{-1}$ ) at $850 \mathrm{hPa}$ at 0600 UTC 12 Nov 1996 . (a) The ERA-40 field. (b) The specific humidity field after the application of a median filter. The solid black line depicts the 2-PVU contour at $320 \mathrm{~K}$.

Alps and values of $\approx 500 \mathrm{~J} \mathrm{~kg}^{-1}$ are present along the streamer's eastern side. In these areas convective activity can be seen in the infrared satellite image (Fig. 6). CIN values are large along the eastern flank of the streamer in the Mediterranean (up to $300 \mathrm{~J} \mathrm{~kg}^{-1}$ ) and over southern France (up to $50 \mathrm{~J} \mathrm{~kg}^{-1}$ ) (not shown). The areas identified as highly unstable by the CTI are in general collocated with elevated CAPE values (Fig. 5b). The different components of the CTI respond to instabilities in different regions. In contrast to $N, N_{w}$ exceeds the set threshold in particularly moist regions located in the Atlantic and the Mediterranean. In the Mediterranean and over northern Europe only the totals index exceeds the instability threshold.

\section{b. Medium-range forecast quality}

Owing to the streamer's influence on the HP event, it is worthwhile to show how accurately the PV streamer at

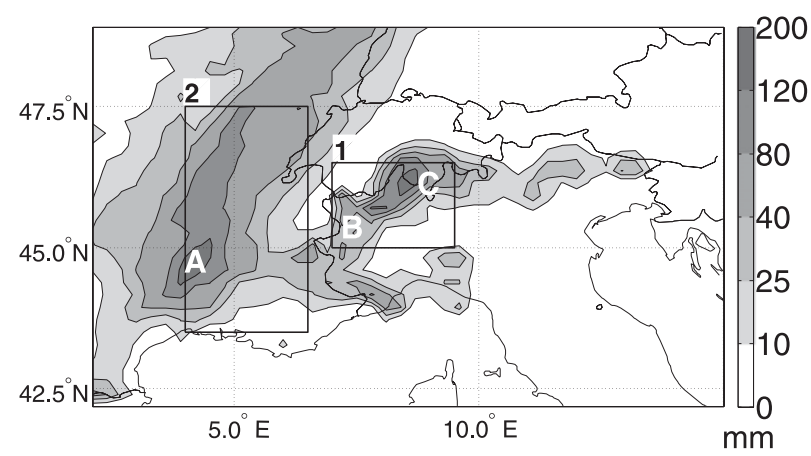

FIG. 3. Precipitation (shaded; mm) accumulated over $24 \mathrm{~h}$ (0600 UTC12 Nov-0600 UTC 13 Nov). The bold black lines indicate the areas used in the discussion in section 5. Label A denotes the French Alps, label B the Piedmont, and label C the Ticino.
1200 UTC 12 November 1996 was forecasted. Such an error analysis will also provide us with good estimates for the modifications in the subsequent sensitivity study. To this end, the upper-level PV field at the $320-\mathrm{K}$ isosurface of the 96-h ECMWF deterministic forecast is compared with the corresponding ERA-40 data (Fig. 7a). The forecasted PV streamer is in the right position (no phase error), but the streamer is broader and shorter than in the ERA-40 data (structural error). As a consequence, the largest errors in the upper-level PV field are located in the tip area and along the flanks of the streamer. The amplitudes of these errors amount to several PVUs (amplitude error).

It might be argued that this discrepancy between forecast and reanalysis is due to the relatively "immature" forecast system that existed in 1996. Yet, a more recent example from 26 October 2004 (Fig. 7b) shows a small phase error but in general a very similar error pattern and underlines the possibility of considerable PV errors in the most sophisticated forecast systems. These observations in terms of amplitude, phase, and structural errors are corroborated by a more systematic study of an ensemble of 13 Alpine HP cases. ${ }^{1}$ The error assessment was undertaken using a newly developed methodology that is outlined in more detail by A. Twitchett and C. Schwierz (2010, unpublished manuscript).

The main conclusions drawn from all 13 case studies investigated show that (i) at 6-h forecast lead times the streamer structures closely match their analysis

\footnotetext{
${ }^{1}$ The analyzed HP dates are 20 Oct 2001, 2 Nov 2002, 16 Nov 2002, 24 Nov 2002, 25 Nov 2002, 31 Oct 2003, 27 Nov 2003, 26 Oct 2004, 1 Nov 2004, 11 Sep 2005, 2 Oct 2005, 17 Sep 2006, and 3 Oct 2006.
} 

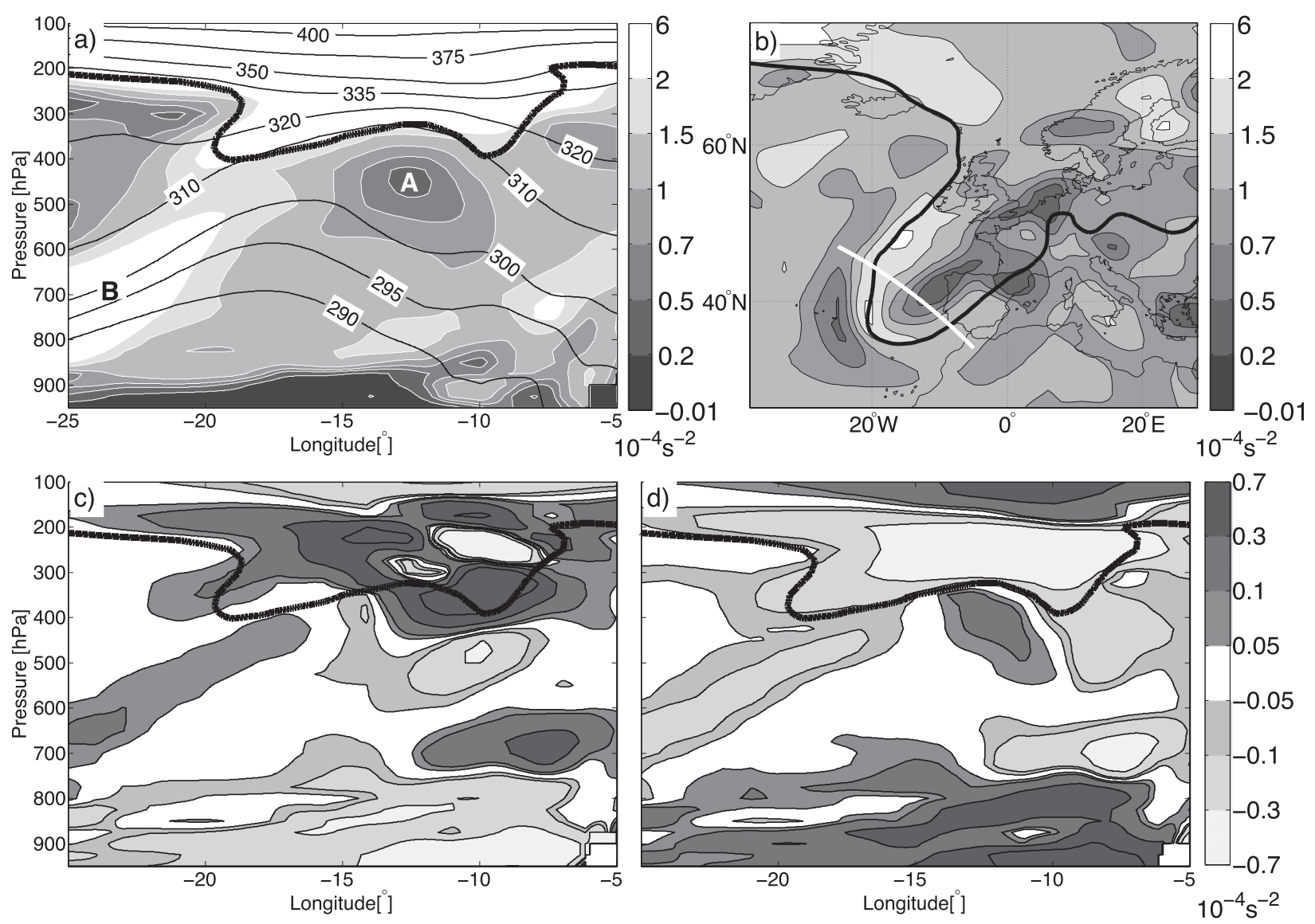

FIG. 4. The situation at 0600 UTC 12 Nov 1996: (a) cross section of $N^{2}$ (shaded), the 2-PVU isoline (bold black line), and isentropes (black lines) in the ERA-40 data; (b) $N^{2}\left(10^{-4} \mathrm{~s}^{-1}\right)$ at $450 \mathrm{hPa}$ in the ERA-40 data, the bold black line is the 2-PVU isoline at $320 \mathrm{~K}$, the bold white line indicates the position of the cross section; (c) differences in $N^{2}$ (experiment - ERA-40; shaded) along the cross section for the TA experiment, the bold black line indicates the location of the 2-PVU isoline in the ERA-40 data; and d) as in (c), but for the TR experiment.

counterparts; (ii) for forecast lead times of $30-54 \mathrm{~h}$, a larger spread of errors is found and there is a tendency toward a too early development of the streamer; and (iii) with lead times of 102 and $106 \mathrm{~h}$, the forecasted streamers are generally shorter and wider than the analysis streamers and break later.

PV modifications of about $\pm(2-3)$ PVU seem justifiable from this limited error climatology. These modifications
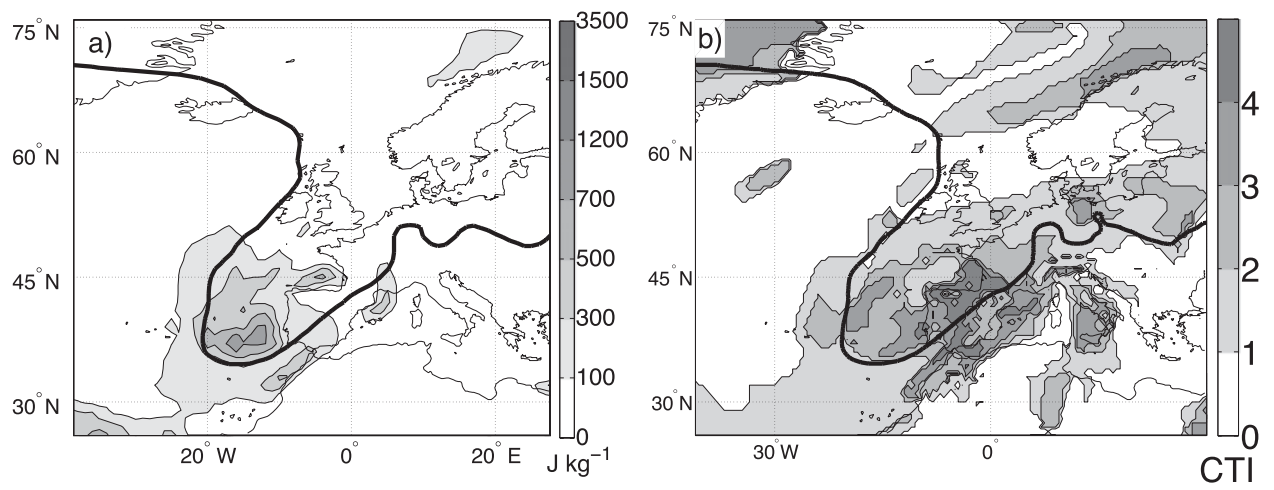

FIG. 5. (a) CAPE field $\left(\mathrm{J} \mathrm{kg}^{-1}\right.$ ) at 0600 UTC 12 Nov 1996 (shaded) calculated from the ERA-40 data. (b) CTI calculated from ERA-40 data for the same time. The bold black line shows the 2-PVU isoline at $320 \mathrm{~K}$. 


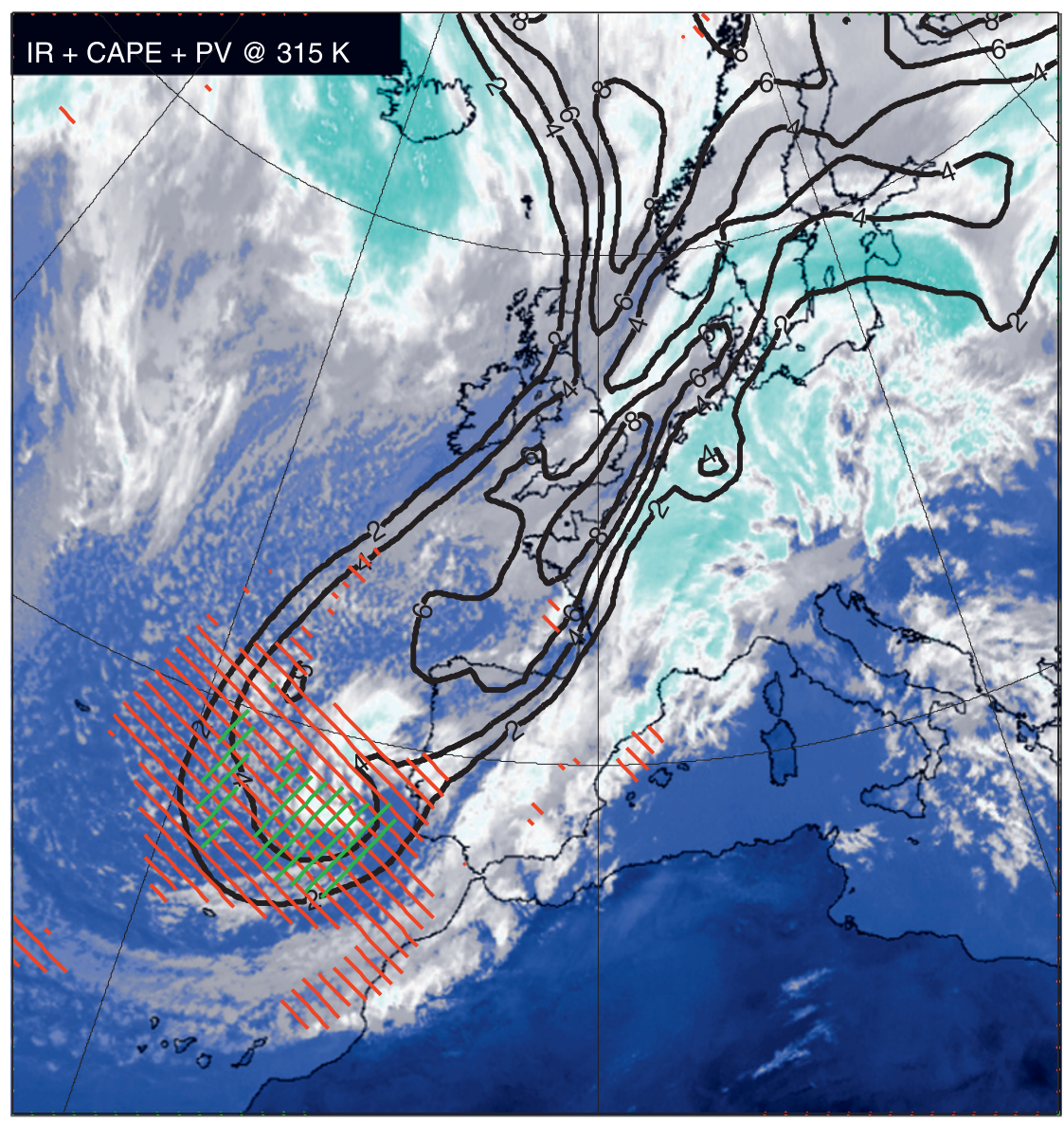

FIG. 6. Meteosat infrared satellite image at 1200 UTC 12 Nov 1996 (color). Black contour lines show the PV in PVU at $315 \mathrm{~K}$. The red-shaded areas indicate CAPE values exceeding $100 \mathrm{~J} \mathrm{~kg}^{-1}$, and green-shaded areas indicate CAPE values $>300 \mathrm{~J} \mathrm{~kg}^{-1}$.

should be predominantly applied to the edges and to the tip of the PV streamer to mimic the tendency of the forecast models to produce too broad, weak, and short streamers.

\section{Alterations of the substructure of the streamer}

\section{a. Overview on the experiments}

To assess the potential impacts of forecast errors described in section $3 \mathrm{~b}$ on this HP event, a series of sensitivity experiments were conducted using the ERA-40 data. Distinct mesoscale substructures of the streamer were altered and the sensitivity of HP to these changes tested.

The following streamer modifications are discussed in the paper (Figs. 8a and 8b): (a) a strengthening (EA) and weakening (ER) of the eastern flank of the streamer (the collocation of the observed mesoscale PV maximum and area of PPVI modifications along the eastern flank is a coincidence), (b) a strengthening (TA) and weakening
(TR) of the tip, and (c) a shorter and broader streamer with a structure that mimics the form of the streamer in the 96-h forecast (SB). The amplitudes of these modifications are, in terms of PV and the change in total energy (see Fita et al. 2007 for details), comparable to the errors found in the 48-h forecast (cf. section 3b). All modifications were made at 0600 UTC 12 November, $36 \mathrm{~h}$ prior to the mature stage of the streamer and $24 \mathrm{~h}$ prior to the HP event. Table 2 provides an overview of the modifications and the resulting changes in PV. We are now interested in how sensitively the static stability, the low-level moisture transport toward the Alps, and the orographic lifting react to the mesoscale alterations of the streamer.

\section{b. Overview on the analysis methods}

\section{1) STABILITY}

The alteration of an upper-level PV structure has an effect on the temperature stratification in the troposphere 

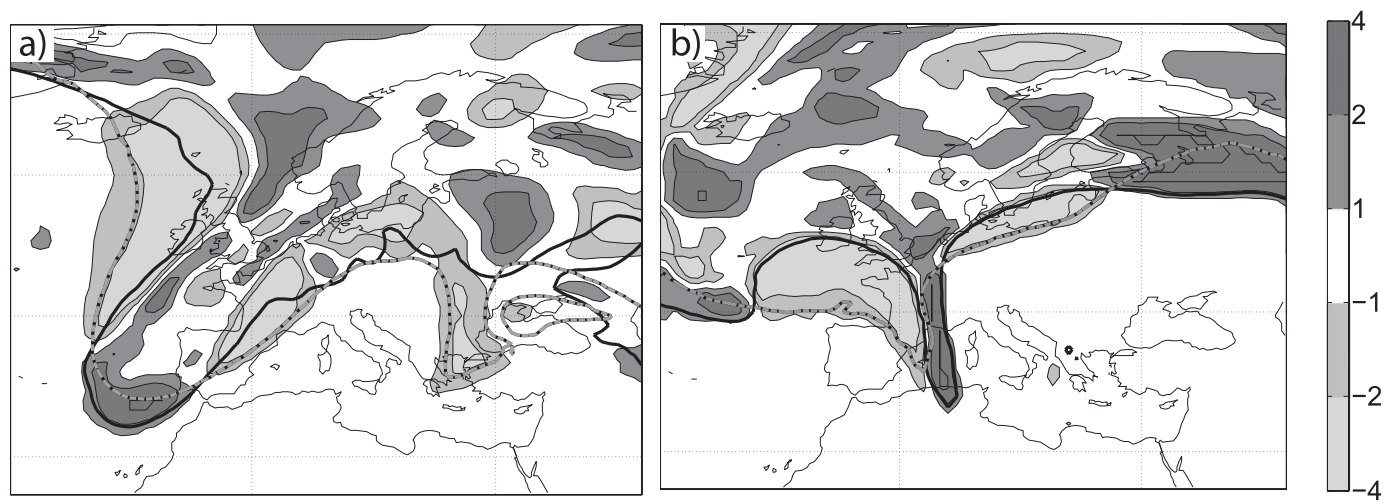

PVU

FIG. 7. (a) Difference (96-h forecast - ERA-40 data) of the PV at $320 \mathrm{~K}$ in PVU at 1200 UTC 12 Nov 1996 (shaded). The bold black line depicts the 2-PVU isoline at $320 \mathrm{~K}$ in the ERA-40 data, and the dashed black-gray bold line indicates the 2-PVU isoline at $320 \mathrm{~K}$ in the forecast. (b) Difference (analysis - 114-h forecast) of the PV at $320 \mathrm{~K}$ in PVU at 1800 UTC 26 Oct 2004 (shaded). The bold black line depicts the 2-PVU isoline at $320 \mathrm{~K}$ in the ECMWF analysis; the dashed black-gray bold line indicates the 2-PVU isoline at $320 \mathrm{~K}$ in the forecast.

below (e.g., Hoskins et al. 1985). The question addressed here is whether these temperature changes have a crucial impact on the static stability. Both temperature and moisture are essential for a destabilization of the environment. The analysis of the moist effects on the stability is complicated by the fact that the PPVI method does not include an adaption of the moisture field to the altered temperature and flow fields. We therefore discuss the impacts of the PPVI on the dry and the moist stability separately. All experiments are carried out with three different moisture treatments (QI, where the absolute moisture content is kept constant), $\mathrm{RH}$ (relative humidity kept constant), and FI (strong spatial filtering; see section $2 \mathrm{c}$ and Fig. $2 \mathrm{~b}$ for more details), allowing a thorough assessment of the sensitivity to moisture effects.

\section{2) Moisture FluX}

As stated in the introduction, an ample and sustained moisture supply is crucial for long-lasting heavy precipitation events (see, e.g., Doswell et al. 1996). Large amounts of water vapor and cloud droplets were transported within the low-level jet along the eastern side of the PV streamer toward the Alps between 0600 and 1200 UTC 12 November (Figs. 9a and 9b). To quantify the sensitivity to the PV alterations, the humidity flux at 0600 UTC 12 November is determined along a vertical cross section located on the eastern side of the streamer (see Fig. 9). More specifically, the product of the water vapor and cloud water times the velocity perpendicular to the cross section is integrated over the area of the cross section:
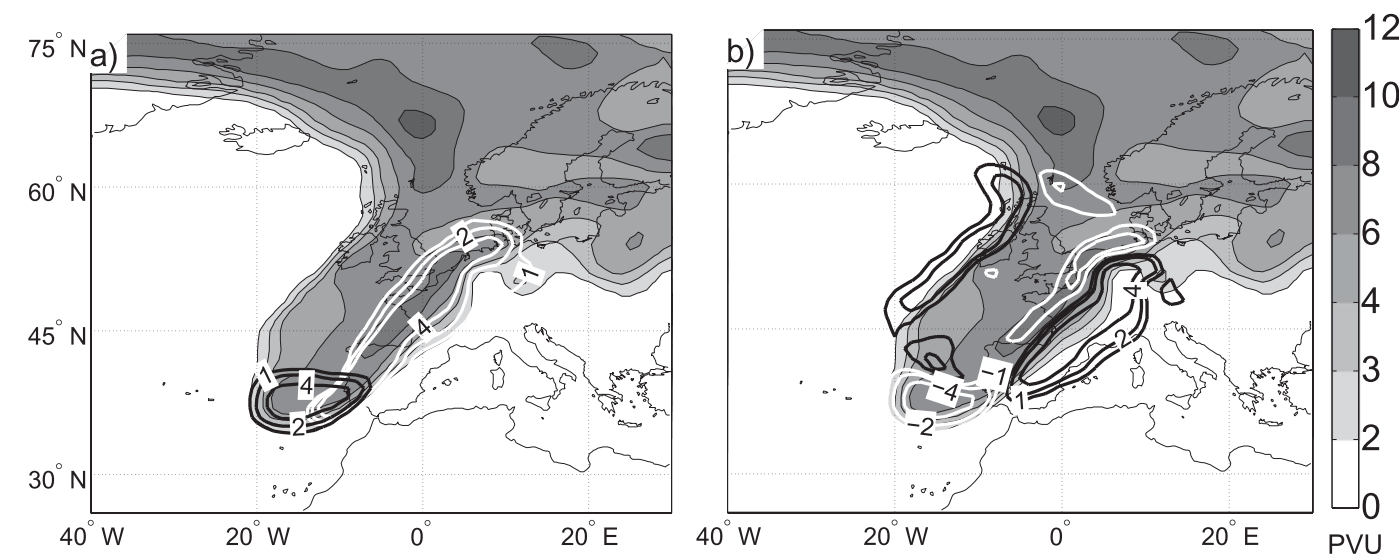

FIG. 8. PV at $320 \mathrm{~K}$ at 0600 UTC 12 Nov 1996 in the ERA-40 data (shaded). The contour lines in (a) indicate the difference between the ERA-40 data and the modified PV field for experiments TA, TR (solid black line), EA, and ER (solid white line). (b) The PV modifications used for the SB experiment; black lines indicate added PV structures and white lines indicate PV structures that were removed. The contour interval is 1,2, and 4 PVU in both panels. 
TABLE 2. Modifications to the PV and the resulting changes in the humidity flux, wind, and inverse Froude number. Changes in PV are quantified giving both the area on the $320-\mathrm{K}$ isosurface where the magnitude of the PV change $>0.1 \mathrm{PVU}$ and the spatial average of the change in this area. For the modification SB, the negative and positive parts of the changes are listed separately. The humidity fluxes $q v$ are computed for the cross section indicated in Fig. 9a, where $v$ is the wind speed normal to the cross section. Values for the humidity flux are listed for the three different moisture treatments (RH, QI, and FI). Here, $\epsilon_{b}$ denotes the bulk estimate of the inverse Froude number. All quantities are valid at 0600 UTC 12 Nov.

\begin{tabular}{|c|c|c|c|c|c|c|c|c|}
\hline \multirow[b]{2}{*}{ Modification } & \multirow[b]{2}{*}{ Short } & \multirow{2}{*}{$\begin{array}{l}+\Delta \mathrm{PV} \\
(\mathrm{PVU})\end{array}$} & \multirow{2}{*}{$\begin{array}{c}\text { area } \\
\left(10^{6} \mathrm{~km}^{2}\right)\end{array}$} & \multicolumn{3}{|c|}{$\begin{array}{c}\Delta q v \\
(\% \text { CTL) }\end{array}$} & \multirow{2}{*}{$\begin{array}{c}\Delta v \\
(\% \mathrm{CTL})\end{array}$} & \multirow[b]{2}{*}{$\epsilon_{b}$} \\
\hline & & & & $\mathrm{RH}$ & QI & FI & & \\
\hline Control & CTL & & & 100 & 100 & 100 & 100 & 0.87 \\
\hline Reduced tip & TR & -1.60 & 93 & 93 & 92 & 55 & 93 & 0.95 \\
\hline Enhanced tip & TA & 2.09 & 109 & 105 & 107 & 65 & 106 & 0.81 \\
\hline Reduced eastern flank & ER & -2.36 & 181 & 66 & 54 & 27 & 57 & 1.52 \\
\hline Enhanced eastern flank & EA & 2.53 & 238 & 122 & 139 & 74 & 135 & 0.61 \\
\hline Short, broad & SB & $-0.94,1.28$ & 307,408 & 92 & 113 & 57 & 118 & 0.61 \\
\hline
\end{tabular}

$$
\frac{1}{\rho g} \iint m v_{\perp} d p d s
$$

where $g$ is the acceleration of gravity; $\rho$ is the density of water; $m$ the mixing ratio; $d s$ and $d p$ are, respectively, the horizontal and vertical dimensions of the cross section; and $v_{\perp}$ denotes the velocity component perpendicular to the cross section. In the control run the water flux amounts to $213000 \mathrm{~m}^{3} \mathrm{H}_{2} \mathrm{O} \mathrm{s}^{-1}$. As stated in Newell et al. (1992), atmospheric rivers can transport water amounts equivalent to the Amazon $\left(\approx 165000 \mathrm{~m}^{3} \mathrm{~s}^{-1}\right)$, or even exceed them.

\section{3) OROGRAPHIC EFFECTS}

A mountain range as high as the Alps exerts a significant impact upon precipitation processes via forced lifting.
The inverse Froude number, $\epsilon=N H_{0} / U$ (Smith 1989), is used here to determine whether or to what degree the southerly flow toward the Alps was blocked by the latter or directed over them. By doing so, many processes that are important for a detailed assessment of the interaction of the flow with the topography are neglected. For instance, Reeves and Lin (2006) discuss the relevance of stable layer formation over the Po River valley for the development of convection, and Rotunno and Ferretti (2001) discuss how low-level barrier jets interacting with the complex topography of the Alps are associated with convergence-driven lifting and precipitation. Here, we simply aim to determine the streamer's impacts on the details of the large-scale flow past elements of the Alpine terrain. An intensification of the precipitation occurs if the air is forced to surmount the
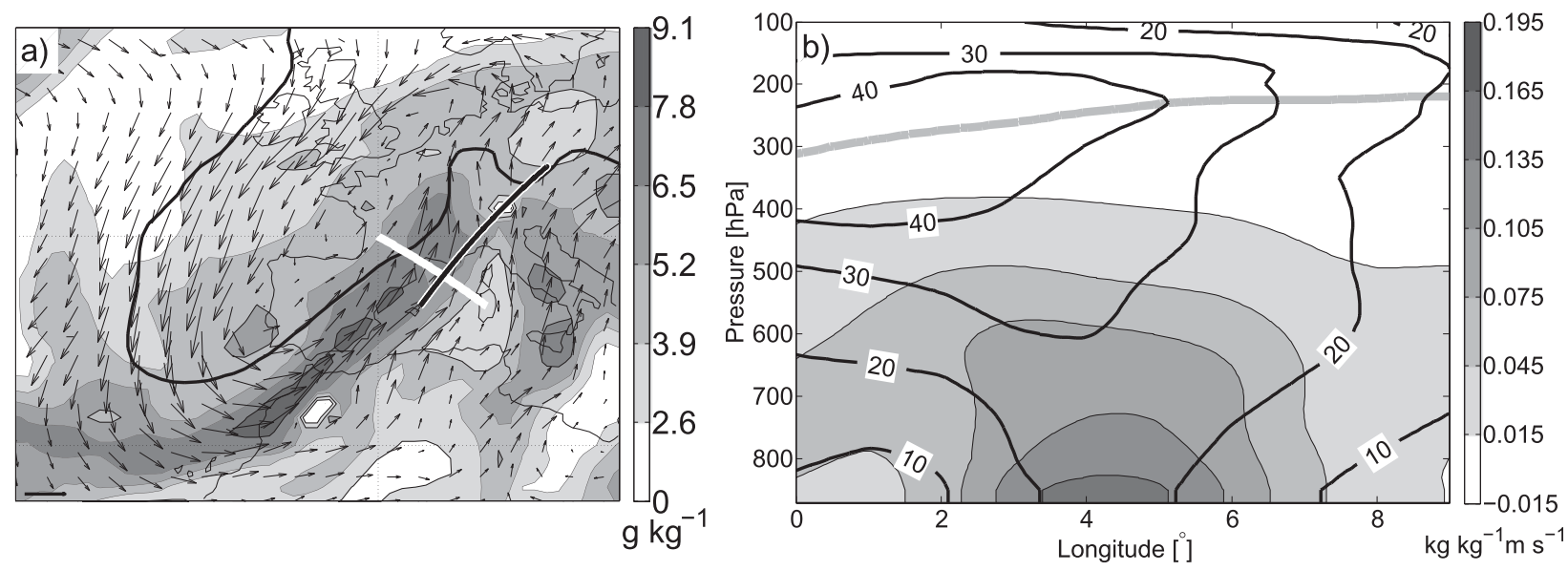

FIG. 9. (a) The humidity distribution ( $\mathrm{g} \mathrm{kg}^{-1}$, shaded) and the wind field at $850 \mathrm{hPa}$ for the ERA-40 data at 0600 UTC $12 \mathrm{Nov}$. The black line is the 2-PVU contour at $320 \mathrm{~K}$. The bold white line indicates the position of the cross section used for the humidity flux calculations. The bold black-white line indicates the cross section used to determine the inverse Froude number. The length of the horizontal line in the lower-left corner indicates a wind speed of $20 \mathrm{~m} \mathrm{~s}^{-1}$. (b) The humidity flux ( $\mathrm{kg} \mathrm{kg}^{-1} \mathrm{~m} \mathrm{~s}^{-1}$, shaded) at 0600 UTC 12 Nov 1996 at the white cross section shown in (a). The solid black lines show the wind field perpendicular to the cross section. The bold gray line indicates the 2-PVU isoline. 


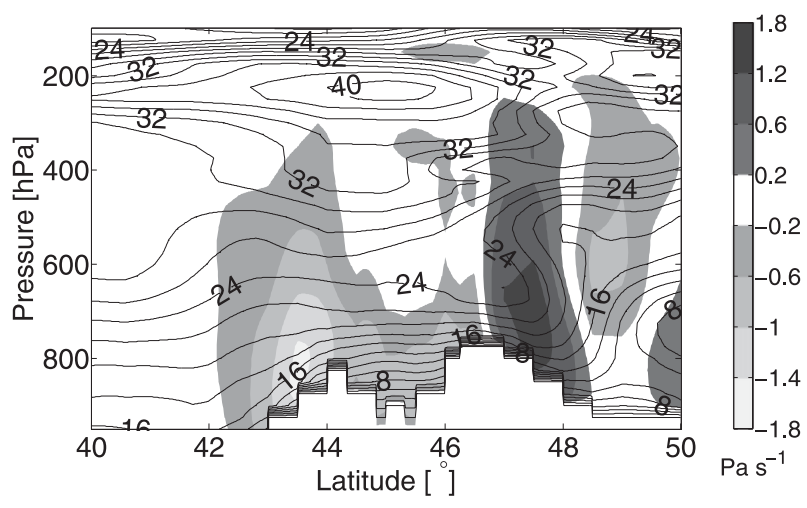

FIG. 10. Vertical wind velocity $\left(\mathrm{Pa} \mathrm{s}^{-1}\right)$ for the control run at 0600 UTC 12 Nov (shaded). Contour lines depict the horizontal wind speed $\left(\mathrm{m} \mathrm{s}^{-1}\right)$ parallel to the cross section (perpendicular to the Alps, as indicated in Fig. 9a).

Alps and consequently substantial lifting condensation takes place (inverse Froude number being smaller than 1). The reverse is true for flow around the Alps (inverse Froude being larger than 1). A direct link exists between the inverse Froude number and an upper-level $\mathrm{PV}$ anomaly. If the PV anomaly is orientated perpendicular to the mountain ridge, as it is in this case, the associated increase of $U$ and decrease in $N$ will facilitate overflow.

We used the bulk estimate for the inverse Froude number as proposed by Reinecke and Durran (2008, see section 2 for more information). In the simulations the bulk inverse Froude number $\epsilon_{b}$ varies between 0.61 and 1.52. A cross section showing the lifting of the air masses in the control run is shown in Fig. 10. The upper-level wind speed approximately perpendicular to the Alps exceeds $40 \mathrm{~m} \mathrm{~s}^{-1}$.

\section{c. Modifications of the streamer's tip}

\section{1) Stability}

Modifications of the PV field have a considerable impact on the dry stability. These changes in $N^{2}$ have a complex three-dimensional structure. This is illustrated in Fig. 4 for the streamer's tip. In Fig. 4a, the upper-level stratospheric high PV (the streamer) and the troposphere underneath the western flank of the streamer (label B), are areas of high static stability. An area of reduced stability is present in the upper troposphere directly underneath the streamer (label A). The atmospheric boundary layer is highly unstable between $25^{\circ}$ and $10^{\circ} \mathrm{W}$. Between these two unstable layers lies a layer of relatively stable stratification.

The effects of the PV modifications in the tip on this structure are illustrated in Figs. $4 \mathrm{c}$ and $4 \mathrm{~d}$. They show the differences $\left(\Delta N^{2}=N_{\text {modified }}^{2}-N_{\text {orig }}^{2}\right)$ for an enhanced
(TA) and a reduced (TR) tip amplitude. Overall, the modifications (TA, see Fig. 4c; TR, see Fig. 4d) have opposite effects on $N^{2}$. Changes in the stability inside the streamer (TA, increased stability; TR, reduced stability) are accompanied by changes in the stability of opposite sign near the surface and in the low-stability region A. The stability changes in the western flank area (B) and on the eastern flank between 750 and $600 \mathrm{hPa}$ follow those inside the streamer. A complete switch of the stratification from unstable (TA and ERA-40) to stable (TR) occurs in the boundary layer area.

The effects of the upper-level PV modifications on the stability become even more complex if moist effects are taken into account. CAPE, CIN, and CTI are used here to characterize changes in the moist stability. All indices take moist and dry effects into account. CAPE and the CTI are sensitive to changes in the moisture and temperature stratifications at different levels and therefore complement each other. CAPE is an integral measure of the convective potential of an entire air column and is quite sensitive to the distribution of near-surface moisture; the simple stability indices, on the other hand, are more robust in this respect, and provide a rough characterization of the low- to midtropospheric stability above the boundary layer. CIN provides information about the amount of energy that needs to be released before convection is initiated.

Here, CAPE reacts particularly sensitively to alterations of the upper-level PV over the oceans (see Figs. 11a and 11d). The temperature changes strongly influence the vertical stability (CAPE) because of the high relative humidity in the near-surface layers. This is in contrast to $N^{2}$ at $850 \mathrm{hPa}$, which decreases both over the ocean and over land (not shown). The changes in $N^{2}$ are located beneath the streamer and the stability along the eastern side of the streamer and in the Alpine region remains almost unchanged by tip PV modifications. CIN is increased to $10 \mathrm{~J} \mathrm{~kg}^{-1}$ in the tip region and to $200 \mathrm{~J} \mathrm{~kg}^{-1}$ along the eastern flank of the streamer in the TR experiment. Hence, while a misrepresentation of the tip will not directly affect the intensity of convection in the target area through destabilization, it can still have an impact through the amount of moisture that is transported toward the Alps (see Table 2).

The CAPE distribution for TA is very similar for the QI and RH approaches (Figs. 11a and 11b). CIN is increased to $20 \mathrm{~J} \mathrm{~kg}^{-1}$ in the tip region and to $150 \mathrm{~J} \mathrm{~kg}^{-1}$ along the eastern side of the streamer in the TR experiment using the QI moisture treatment (not shown). In the FI approach, the low-level moisture is redistributed by the filter and the CAPE pattern looks different with considerably higher CAPE values over the Atlantic (Fig. 11c). 


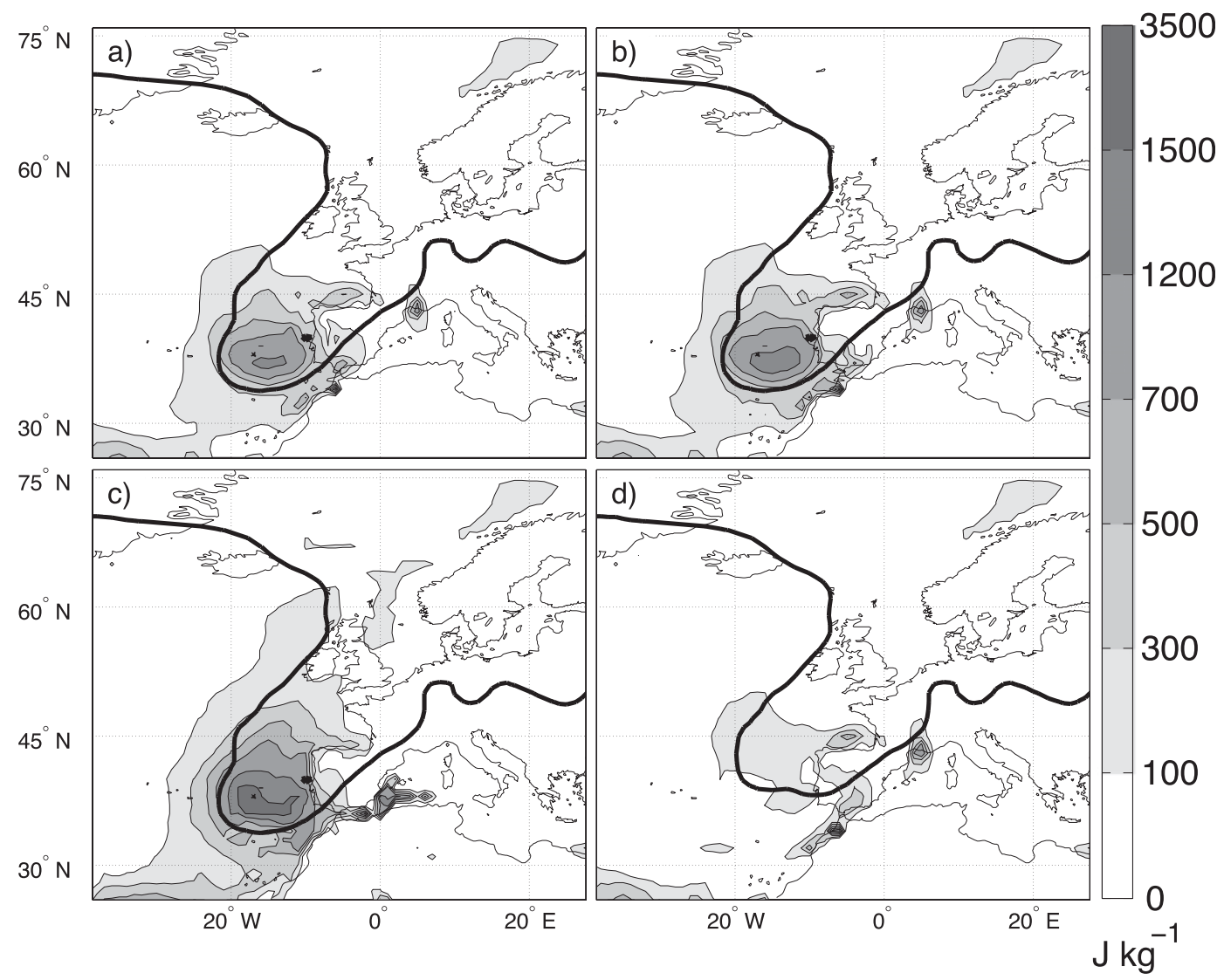

FIG. 11. CAPE values $\left(\mathrm{J} \mathrm{kg}^{-1}\right)$ for the experiment with an enhanced tip (TA, shaded) at 0600 UTC 12 Nov 1996 using moisture treatments (a) RH, (b) QI, and (c) FI. (d) CAPE values $\left(\mathrm{J} \mathrm{kg}^{-1}\right)$ for the experiment with a reduced tip (TR, shaded) at 0600 UTC 12 Nov 1996 for the RH moisture treatment. The bold black line is the 2-PVU contour at $320 \mathrm{~K}$.

\section{2) Moisture FluX}

In the TA experiment the moisture fluxes are larger than in the control run (Table 2), but the precipitation averaged over the two control areas is slightly lower in the French Alps and almost zero in the Swiss Alps (Table 3). The reason for these discrepancies is a cyclonic wrap-up of the enhanced streamer tip that leads to a westward shift of the moisture flux maximum. In the TR setting the streamer does not start to roll up cyclonically and moisture fluxes toward both the French and the Swiss Alps, albeit of reduced magnitude, are sustained (not shown).

\section{d. Modifications of the streamer's eastern flank}

\section{1) StABiLiTy}

The effects on the stability are complex in the area of the French Alps, where significant amounts of precipitation fell. Dry stability $\left(N^{2}\right)$ increases (decreases) for EA (ER) down to about $700 \mathrm{hPa}$. Between $700 \mathrm{hPa}$ and the model topography at approximately $750 \mathrm{hPa}$, the stability decreases (increases) for EA (ER) (not shown).

Looking at the moist stability using the CTI, an increase (decrease) of the stability is observed for ER (EA) under the streamer tip, under the eastern side, and along the eastern side of the streamer. The stabilization for ER is robust for all three moisture treatments with the strongest amplification observed for the FI approach and the weakest response for the RH approach. The destabilization in the EA case is most pronounced when using the QI approach. In the area of the French Alps, the CTI indicates reduced (enhanced) stability for EA (ER).

\section{2) Moisture fluXes}

The PV modifications along the flanks of the streamer have a large effect on the low-level wind field and thereby the moisture flux. More quantitatively, a reduction (increase) of the PV along the eastern flank is accompanied by a reduction of $43 \%$ (enhancement of $35 \%$ ) of the wind field at the cross section (Fig. 9a) at 
TABLE 3. Observed and modeled rain sums in mm accumulated between 0600 UTC 12 Nov and 0600 UTC 13 Nov averaged over the two boxes shown in Fig. 3. The model-derived precipitation is separated into convective and large-scale precipitation. Values are listed for the moisture treatments $\mathrm{RH}$ and QI.

\begin{tabular}{|c|c|c|c|c|c|c|c|c|c|c|c|c|c|}
\hline \multirow[b]{3}{*}{ Modification } & \multirow[b]{3}{*}{ Short } & \multicolumn{6}{|c|}{ French Alps } & \multicolumn{6}{|c|}{ Ticino } \\
\hline & & \multicolumn{2}{|c|}{ Sum } & \multicolumn{2}{|c|}{ Convective } & \multicolumn{2}{|c|}{ Large scale } & \multicolumn{2}{|c|}{ Sum } & \multicolumn{2}{|c|}{ Convective } & \multicolumn{2}{|c|}{ Large scale } \\
\hline & & $\mathrm{RH}$ & QI & RH & QI & RH & QI & $\mathrm{RH}$ & QI & $\mathrm{RH}$ & QI & RH & QI \\
\hline Observation & OBS & 49 & & & & & & 36 & & & & & \\
\hline Control & CTL & 57 & & 30 & & 26 & & 16 & & 2 & & 14 & \\
\hline Reduced tip & TR & 36 & 35 & 19 & 20 & 17 & 15 & 22 & 21 & 3 & 4 & 18 & 17 \\
\hline Enhanced tip & TA & 36 & 39 & 18 & 20 & 18 & 19 & 5 & 6 & 0 & 0 & 5 & 5 \\
\hline Reduced eastern flank & ER & 32 & 18 & 19 & 13 & 13 & 5 & 9 & 12 & 3 & 4 & 6 & 7 \\
\hline Enhanced eastern flank & EA & 53 & 58 & 23 & 26 & 30 & 32 & 48 & 52 & 10 & 12 & 38 & 41 \\
\hline Short, broad & SB & 29 & 32 & 17 & 18 & 11 & 14 & 34 & 35 & 8 & 7 & 25 & 28 \\
\hline
\end{tabular}

0600 UTC 12 November. Consequently, the moisture flux through the cross section indicated in Fig. 9a varies between $141000 \mathrm{~m}^{3} \mathrm{~s}^{-1}(66 \%, \mathrm{ER})$ and $260000 \mathrm{~m}^{3} \mathrm{~s}^{-1}$ $(122 \%, \mathrm{EA})$ for the RH moisture treatment (Table 2). If the specific humidity is kept constant (moisture treatment QI), the range of recorded values is larger and varies between $116000 \mathrm{~m}^{3} \mathrm{~s}^{-1}(54 \%)$ for the ER case and $296000 \mathrm{~m}^{3} \mathrm{~s}^{-1}$ (139\%) for the EA case (valid at 0600 UTC 12 November). The range is larger than for the RH cases because of additional temperature changes that affect the RH treatment. A positive upper-level PV anomaly induces colder temperatures at the surface in the EA setting. If the relative humidity is kept constant $(\mathrm{RH})$, the colder temperatures will lead to a decrease in specific humidity. Hence in the RH setting, the positive contribution to the flux by the stronger low-level winds is partially cancelled by this negative humidity effect. Using the FI approach, the moisture fluxes amount to approximately $50 \%$ of the values recorded for QI and $\mathrm{RH}$ for both experiments.

\section{3) INVERSE FROUDE NUMBER AND THE FLOW IN THE VICINITY OF THE ALPS}

Changes of the upper-level PV along the eastern flank of the streamer affect the flow regime in the vicinity of the Alps substantially. The southerly flow, which impinges on the Alps from the south, varies between approximately $40 \mathrm{~m} \mathrm{~s}^{-1}$ in the control run (Fig. 10), more than $50 \mathrm{~m} \mathrm{~s}^{-1}$ for an enhanced eastern flank (EA), and approximately $20 \mathrm{~m} \mathrm{~s}^{-1}$ for a reduced (ER) eastern flank of the streamer (Fig. 12). This southerly flow is strongest (weakest) in the EA (ER) experiment throughout the troposphere. As a consequence, ER is the only PV modification where $\epsilon_{b}>\epsilon_{\text {crit }}$ and a transition of the flow regime occurs between ER ( $\epsilon_{b}=1.52$, blocked flow $)$ and the control run $\left(\epsilon_{b}=0.87\right.$, flow over the Alps).

A stronger streamer leads to a destabilization of the atmosphere and to an increase of the cross-barrier wind speed, both of which contribute to a reduction in $\epsilon$ and enhanced flow over the mountains. This lifting in its turn enhances orographic precipitation. Strong maxima in the vertical wind velocity, which exceed the intensity of the vertical winds in the control run, are found in the EA experiment (Fig. 12a). On the upstream side of the Alps the air is lifted, whereas sinking motion occurs on the downstream side. Coming back to the simple model proposed by Doswell et al. (1996), a strong eastern flank of the streamer influences both the moisture flux and the orographic lifting in a reinforcing way.

\section{e. A broader and shorter streamer}

In this experiment the structure of the streamer is modified using the stretching tool described in section $2 b$. The SB streamer resembles the structure of the streamer in the $96-\mathrm{h}$ forecast but it is located about $5^{\circ}$ farther east over the Alps (cf. Fig. 13a).

\section{1) STABILITY}

Both CAPE and the CTI indicate that the atmosphere is less stable directly underneath the extended eastern flank of the SB streamer (see Fig. 13a). CAPE reacts again very sensitively in regions with high low-level moisture concentrations. In the CAPE field the atmosphere is particularly unstable over the Mediterranean off the coast of France. CIN values are increased in these areas. The land-sea contrast is less pronounced in the CTI. Along the Alpine south side, both CAPE and the CTI register a labilization of the atmosphere, which is strongest in the QI moisture treatment but also substantial in the RH moisture experiment.

\section{2) Moisture Flux}

The southerly wind maximum along the eastern flank of the streamer is shifted by about $4^{\circ}$ to the east in the SB experiment at upper levels as well as at the surface, but the amplitude is slightly higher (about $2-3 \mathrm{~m} \mathrm{~s}^{-1}$ larger) in the latter compared to the ERA-40 data (not shown). 

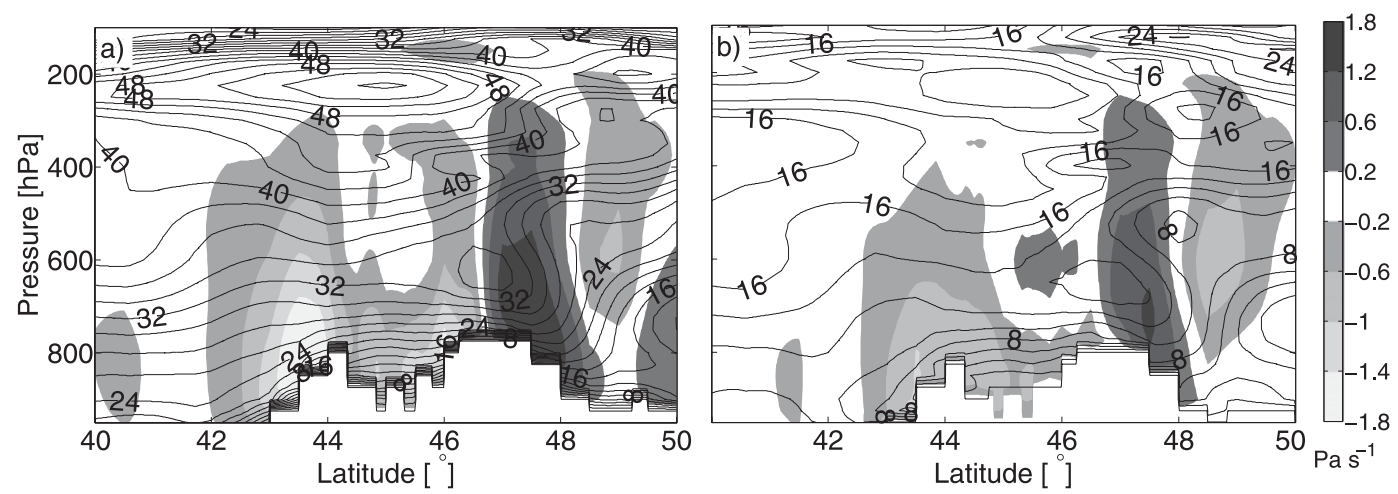

FIG. 12. As in Fig. 10, but for experiments (a) EA and (b) ER.

The integrated humidity flux through the cross section is slightly larger (13\%) in the SB experiment if the QI moisture treatment is used and reduced by $8 \%$ if the $\mathrm{RH}$ moisture treatment is applied than in the ERA-40 data. The reduction in the moisture flux using the $\mathrm{RH}$ moisture treatment is due to the previously described temperature effect. The temperature in the lowest levels is approximately $4^{\circ}-5^{\circ} \mathrm{C}$ colder in the $\mathrm{SB}$ experiment, leading to a considerable reduction in the moisture content of the air if the relative humidity is kept constant.

\section{3) INVERSE FROUDE NUMBER AND THE FLOW IN THE VICINITY OF THE ALPS}

The southerly wind component perpendicular to the Alps is about $10 \mathrm{~m} \mathrm{~s}^{-1}$ faster in the SB experiment compared to the control run (Fig. 13b). The lifting on the upstream side and the sinking motion on the downstream side of the Alps are slightly stronger $\left(0.2 \mathrm{~m} \mathrm{~s}^{-1}\right)$ than in the control run. The eastward shift of the streamer positions the maximum of the incident flow directly at the cross section. Strong upper-level winds of up to $54 \mathrm{~m} \mathrm{~s}^{-1}$ contribute to a decrease of $\epsilon_{b}$ to 0.61 . The lifting at the first mountain ridge $\left(43^{\circ} \mathrm{N}\right)$ in the experiment is comparable to the control run, whereas the vertical motion at the second ridge $\left(46^{\circ} \mathrm{N}\right)$ is enhanced in the experiment.

\section{Precipitation}

In this section the effects of the PV modifications on the precipitation are discussed based on the model simulations. To this end, the wind and temperature fields from the PPVI are combined with the three different moisture fields and used as the initial conditions for the CHRM model. The precipitation is validated in the two areas indicated by the boxes in Fig. 3. To compare the different experiments, we analyze precipitation fields after an integration time of $24 \mathrm{~h}$ (see Table 3).

The large-scale structure of the precipitation with one maximum located along the Swiss Alpine south side (region 1) and one maximum over the French Alps (region 2) is well captured by the model. Along the Swiss Alpine south side (region 1), the rain amount is underestimated in the control run (Fig. 14a), where an area mean of $16 \mathrm{~mm} \mathrm{(100 \% )} \mathrm{fell} \mathrm{over} 24 \mathrm{~h}$ in the target area,
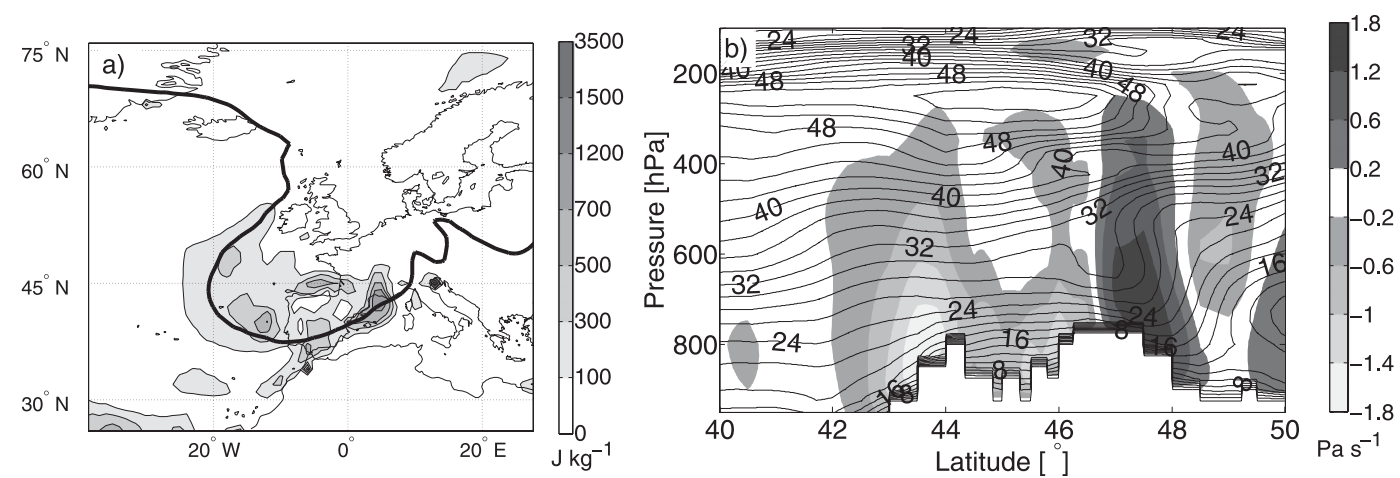

FIG. 13. (a) CAPE $\left(\mathrm{J} \mathrm{kg}^{-1}\right)$ for experiment SB at 0600 UTC 12 Nov 1996. The boldface line indicates the 2-PVU line at $320 \mathrm{~K}$. (b) Vertical wind velocity $\left(\mathrm{Pa} \mathrm{s}^{-1}\right.$ ) for experiment SB at 0600 UTC 12 Nov 1996 (shaded). Contour lines depict the horizontal wind speed $\left(\mathrm{m} \mathrm{s}^{-1}\right)$ parallel to the cross section (perpendicular to the Alps as indicated in Fig. 9a). 

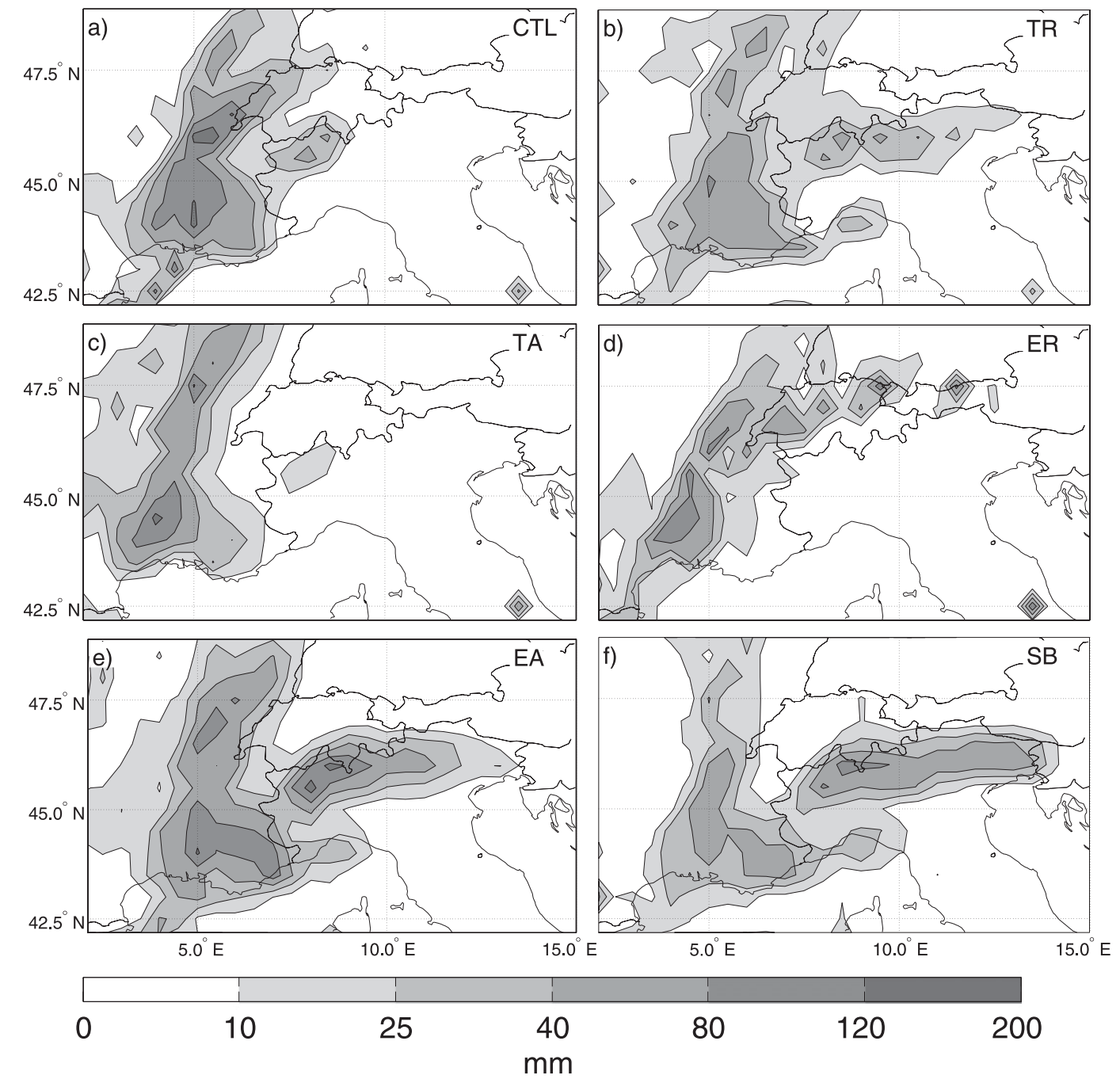

FIG. 14. The 24-h accumulated precipitation (0600 UTC 12 Nov-0600 UTC 13 Nov) (mm, shaded) for (a) the control run and the (b) TR, (c) TA, (d) ER, (e) EA, and (f) SB experiments using the RH moisture treatment.

while the interpolated rain gauge dataset registered $36 \mathrm{~mm}$. The precipitation maximum over the French Alps (region 2) is better captured and slightly overestimated by $8 \mathrm{~mm}(57 \mathrm{~mm}, 100 \%)$. In the model more than $85 \%$ of the precipitation along the Swiss Alpine south side and more than $46 \%$ of the precipitation over the northern French Alps is large-scale precipitation, whereas the precipitation maximum over the southern French Alps is mainly convectively driven.

Averaged over the box located to the south of the Swiss Alps (region 1), the precipitation values in the different experiments with moisture treatment $\mathrm{RH}$ range from $5 \mathrm{~mm}(45 \%)$ in the TA setup to $48 \mathrm{~mm}(300 \%)$ in the EA setup (see Fig. 14). In the TA experiment the moisture fluxes and the main precipitation area are shifted to the west compared to the control run (Fig. 14c).
The precipitation maxima are located north of the Alps in the ER experiment (Fig. 14d). This is in good agreement with the enhanced orographic blocking and flow tendency around the mountains (see section 4) and the fact that the main moisture flux is directed around the Alps along their western flank. In the setup with a shorter and broader streamer, the precipitation maximum along the south side of the Alps $(34 \mathrm{~mm})$ is higher than in the control run and extending eastward along the Alps (Fig. 14f). The shape and amplitude of this precipitation signature are closer to the observed structure than the control run. This is due to a shift in the location of the main humidity transport route. The second precipitation maximum over the French Alps is underestimated in this experiment compared to the observations and the control run. The model precipitation is mainly triggered by the 
large-scale flow in the SB experiment along the Alpine south side. The convective contribution of about $24 \%$ is however larger than that in the control run. This is in good agreement with the larger CAPE and CTI values in this area in this experiment (see Fig. 13a).

Overall, the difference in the accumulated area mean precipitation between the QI and the $\mathrm{RH}$ moisture treatments does not exceed $5 \mathrm{~mm}$ in any of the experiments except for the ER experiment where the precipitation in the French Alps is very sensitive to the moisture treatment (see Table 3). In the ER experiment, the humidity fluxes between the moisture treatment QI and RH determined at 0600 UTC 12 November differ by only $18 \%$ but the precipitation sums integrated over $24 \mathrm{~h}$ differ by $42 \%$ (see Table 2 ). The humidity fluxes are calculated directly after the PPVI and reflect only the instantaneous situation; whereas the precipitation depends on the moisture fluxes over a time span of $24 \mathrm{~h}$. Integrated over the time span of $24 \mathrm{~h}, 629000 \mathrm{~m}^{3}$ are registered at the cross section for $\mathrm{RH}$ moisture treatment. In the ER experiment using the QI approach, the humidity fluxes become progressively weaker, and integrated over the $24-\mathrm{h}$ period, $556000 \mathrm{~m}^{3}(88 \%$ of the RH treatment) are recorded.

\section{Summary and conclusions}

This study presents a detailed analysis of the forcing factors that lead to a heavy precipitation event that occurred along the Alpine south side in November 1996. A piecewise PV inversion approach is used to analyze the dynamical and physical mechanisms that lead to the event. In addition to the dynamical analysis, this study contains methodology-oriented components that are helpful in discussing three approaches to adapting the moisture field after the PV inversion, as well as containing a detailed comparison of various indicators of dry and moist stability.

\section{a. Discussion of the three moisture treatments}

In section 2, we propose three approaches to treat the moisture distribution when using PPVI, namely, (i) to apply a strong filter to the moisture field to remove all structures below the planetary scale (FI), (ii) to keep the absolute humidity constant and only correct areas of supersaturation (QI), and (iii) to keep the relative humidity constant $(\mathrm{RH})$. A detailed discussion of the effects of the three moisture treatments on the stability and the amount of moisture that is transported toward the Alps is given in section 4. In summary it can be stated that for the QI and RH both the stability and the moisture fluxes are very similar. For the FI approach, on the other hand, we find widespread and nonlocal effects on the stability and a significant reduction in the amplitude of the moisture fluxes toward the Alps.

We do not therefore recommend the use of a strongly filtered or a climatological mean moisture field for mesoscale modifications of the PV. This is further underlined considering the partition principle of PV and the fact that only weak PV modifications were introduced where accordingly weak effects can be expected on the moisture field (linear scale argument). The amplitude of the moisture error introduced by the filtering is expected to be larger than the inconsistencies between an altered flow field and the original moisture field, both in its spatial extent and its amplitude. In addition, relevant information on the synoptic-scale moisture distribution is lost through the filtering process.

Keeping the relative humidity constant is the physically most consistent method from a stability analysis point of view. We have used this approach as a reference method throughout the paper. No definitive solution to the moisture treatment problem is offered. In our results, the sensitivity of the vertical stability to the moisture treatment is comparable in magnitude to the response to the actual PV alteration. This indicates how important the moisture field can be for extratropical analyses and that further effort needs to be put into the development of moist PV inversion techniques such as the approach proposed by McTaggart-Cowan et al. (2003).

\section{b. Summary of the PPVI experiments}

Previous climatological and case-based studies have shown that very often so-called PV streamers located over western Europe are the key synoptic-scale drivers behind the heavy precipitation events. As illustrated here, current-state NWP models still have problems with the correct prediction and representation of these PV streamers. An error analysis reveals that the streamers tend to be too broad and too short in the forecasts.

Piecewise potential vorticity inversion is used to assess the effects of modifications of the upper-level PV distribution, which resemble the typical forecast errors, on the precipitation for the November 1996 case. The modifications are similar, both in their magnitude and structure, to the observed forecast errors. The modifications of mesoscale PV structures located in the tip and along the flanks of the streamer are evaluated with regard to their impacts on the stability, the moisture flux, and the orographic precipitation forcing.

\section{1) StabiLity}

The impacts of a mesoscale PV anomaly on the stability in general have a complex three-dimensional structure and are not limited to upper-tropospheric levels. Areas of low stability both directly beneath the PV 
streamer as well as in the lowest layer of the atmosphere between the ground and approximately $850 \mathrm{hPa}$ are very sensitive to modifications of the upper-level PV. Over the ocean, where the air is very moist, small changes in the low-level temperature due to upper-level PV modifications have a major impact on the CAPE. The impacts of the upper-level field on the stability over the precipitation area in the Alps are relatively limited and change over time. Destabilization is therefore a secondorder effect in the formation of HP in the Alps.

\section{2) Moisture fluX}

Changes along the eastern flank of the PV streamer have a crucial impact on the moisture transport toward the Alps, influencing both the amount of moisture that is transported and the location where the strongest moisture fluxes impinge upon the Alps. The moisture treatment has a substantial influence on the magnitude of the moisture fluxes.

\section{3) OROGRAPHIC FORCING}

The upper-level PV structure has a crucial impact on whether the air is forced to flow over or around the topographic obstacle. Precipitation is enhanced for overflow conditions with a strong positive signal in the local lifting. An upper-level PV anomaly that is situated to the west of and orientated perpendicular to the mountain chain, as is the case for this example, causes a reduction in the stability and an increase in the flow component perpendicular to the mountain. As a consequence, the flow is more likely to cross the barrier, as quantitatively assessed by the inverse Froude number.

The outcome of the PV modification experiments clearly shows that the structural errors often associated with the forecasting of PV streamers can have a decisive impact on the quality of the precipitation forecast.

Acknowledgments. This project has been partially funded by NCCR Climate. We wish to thank Richard Moore and Christoph Schär for fruitful discussions concerning the moisture treatment. We thank MeteoSwiss for providing the ERA-40 data, Dani Lüthi for giving advice using the CHRM, Marco Stoll and Dani Leuenberger for providing the CAPE routine, and the two reviewers for many good suggestions and for greatly enhancing the clarity of the text.

\section{REFERENCES}

Appenzeller, C., and H. C. Davies, 1992: Structure of stratospheric intrusions into the troposphere. Nature, 358, 570-572.

Bolton, D., 1980: The computation of equivalent potential temperature. Mon. Wea. Rev., 108, 1046-1053.

Bougeault, P., and Coauthors, 2001: The MAP special observing period. Bull. Amer. Meteor. Soc., 82, 433-462.
Buzzi, A., N. Tartaglione, and P. Malguzzi, 1998: Numerical simulations of the 1994 Piedmont flood: Role of orography and moist processes. Mon. Wea. Rev., 126, 2369-2383.

Davis, C. A., 1992: Piecewise potential vorticity inversion. J. Atmos. Sci., 49, 1397-1411.

Didone, M., 2006: Performance and error diagnosis of global and regional NWP models. Ph.D. thesis 16597, ETH Zurich, 113 pp.

Dirren, S., M. Didone, and H. C. Davies, 2003: Diagnosis of "forecast-analysis" differences of a weather prediction system Geophys. Res. Lett., 30, 2060, doi:10.1029/2003GL017986.

Doswell, C. A., III, H. E. Brooks, and R. A. Maddox, 1996: Flash flood forecasting: An ingredients-based methodology. Wea. Forecasting, 11, 560-581.

Eckhardt, S., A. Stohl, H. Wernli, P. James, C. Foster, and N. Spichtiger, 2004: A 15-year climatology of warm conveyor belts. J. Climate, 17, 218-237.

Emanuel, K. A., 1994: Atmospheric Convection. 3d ed. Oxford University Press, 580 pp.

Fehlmann, R., 1997: Dynamics of seminal PV elements. Ph.D. thesis 12229, ETH Zurich, 143 pp.

— south-side precipitation. Meteor. Atmos. Phys., 72, 223-231.

$\longrightarrow, \ldots$, and H. C. Davies, 2000: An Alpine rainstorm: Sensitivity to the mesoscale upper-level structure. Wea. Forecasting, 15, 4-28.

Fita, L., R. Romero, and C. Ramis, 2007: Objective quantification of perturbations produced with a piecewise PV inversion technique. Ann. Geophys., 25, 2335-2349.

Frei, C., and C. Schär, 1998: A precipitation climatology over the Alps from high-resolution rain-gauge observations. Int. J. Climatol., 18, 873-900.

Fuhrer, O., and C. Schär, 2005: Embedded cellular convection in moist flow past topography. J. Atmos. Sci., 62, 2810-2828.

Funatsu, B. M., and D. W. Waugh, 2008: Connections between potential vorticity intrusions and convection in the eastern tropical Pacific. J. Atmos. Sci., 65, 987-1002.

George, J. J., 1960: Weather Forecasting for Aeronautics. Academic Press, 673 pp.

Gheusi, F., and H. C. Davies, 2004: Autumnal precipitation distribution on the southern flank of the Alps: A numericalmodel study of the mechanisms. Quart. J. Roy. Meteor. Soc., 130, 2125-2152.

Grazzini, F., 2007: Predictability of a large-scale flow conducive to extreme precipitation over the western Alps. Meteor. Atmos. Phys., 3-4, 123-138.

Hakim, G. J., D. Keyser, and L. F. Bosart, 1996: The Ohio valley wave-merger cyclogenesis event of 25-26 January 1978. Part II: Diagnosis using quasigeostrophic potential vorticity inversion. Mon. Wea. Rev., 124, 2176-2205.

Hoinka, K. P., and H. C. Davies, 2007: Upper-tropospheric flow features and the Alps: An overview. Quart. J. Roy. Meteor. Soc., 133, 847-865.

Holtslag, A. A. M., and B. A. Boville, 1993: Local versus nonlocal boundary-layer diffusion in a global climate model. J. Climate, 6, 1825-1842.

Hoskins, B. J., M. E. McIntyre, and A. W. Robertson, 1985: On the use and significance of isentropic potential vorticity maps. Quart. J. Roy. Meteor. Soc., 111, 877-946.

Jacobeit, J., 1987: Variations of trough positions and precipitation patterns in the Mediterranean area. J. Climatol., 7, 453-476.

Kessler, E., 1969: On the Distribution and Continuity of Water Substance in Atmosphere Circulation. Meteor. Monogr., No. 46, Amer. Meteor. Soc., 84 pp. 
Koch, P., 2004: Novel perspectives of jet-stream climatologies and events of heavy precipitation on the Alpine southside. Ph.D. thesis 15622, ETH Zurich, 203 pp.

Lin, Y. L., R. D. Farley, and H. D. Orville, 1983: Bulk parameterization of the snow field in a cloud model. J. Appl. Meteor., 22, 1065-1092.

Lüthi, D., A. Cress, H. C. Davies, C. Frei, and C. Schär, 1996: Interannual variability and regional climate simulations. Theor. Appl. Climatol., 53, 185-209.

Majewski, D., 1999: HRM-Users's guide. German Weather Service Tech. Rep., 107 pp.

Martius, O., E. Zenklusen, C. Schwierz, and H. C. Davies, 2006: Episodes of Alpine heavy precipitation with an overlying elongated stratospheric intrusion: A climatology. Int. J. Climatol., 26, 1149-1164.

Massacand, A. C., H. Wernli, and H. C. Davies, 1998: Heavy precipitation on the Alpine southside: An upper-level precursor. Geophys. Res. Lett., 25, 1435-1438.

,-- , and — , 2001: Influence of upstream diabatic heating upon an Alpine event of heavy precipitation. Mon. Wea. Rev., 129, 2822-2828.

McTaggart-Cowan, R., J. R. Gyakum, and M. K. Yau, 2003: Moist component potential vorticity. J. Atmos. Sci., 60, 166-177.

Mecikalski, J. R., and K. M. Bedka, 2006: Forecasting convective initiation by monitoring the evolution of moving cumulus in daytime GOES imagery. Mon. Wea. Rev., 134, 49-78.

Mellor, G. L., and T. Yamada, 1974: A hierarchy of turbulent closure models for planetary boundary layers. J. Atmos. Sci., 31, 1791-1806.

Miller, R. C., 1972: Notes on analysis and severe-storm forecasting procedures of the Air Force Global Weather Central. Air Weather Service Tech. Rep. 200, 190 pp. [Available from Air Weather Service Technical Library, 859 Buchanan St., Scott AFB, IL 62225-5118.]

Morgenstern, O., and H. C. Davies, 1999: Disruption of an upperlevel PV-streamer by orographic and cloud-diabatic effects. Contrib. Atmos. Phys., 72, 173-186.

Newell, R. E., N. E. Newell, Y. Zhu, and C. Scott, 1992: Tropospheric rivers?-A pilot study. Geophys. Res. Lett., 19, 2401-2404.

Ólafsson, H., and P. Bougeault, 1997: The effect of rotation and surface friction on orographic drag. J. Atmos. Sci., 54, 193-210.
Pierrehumbert, R., and B. Wyman, 1985: Upstream effects of mesoscale mountains. J. Atmos. Sci., 42, 977-1003.

Reale, O., L. Feudale, and B. Turato, 2001: Evaporative moisture sources during a sequence of floods in the Mediterranean region. Geophys. Res. Lett., 28, 2085-2088.

Reeves, H. D., and Y. L. Lin, 2006: Effect of stable layer formation over the Po valley on the development of convection during MAP IOP-8. J. Atmos. Sci., 63, 2567-2584.

Reinecke, P. A., and D. R. Durran, 2008: Estimating topographic blocking using a Froude number when the static stability is nonuniform. J. Atmos. Sci., 65, 1035-1048.

Rotunno, R., and R. Ferretti, 2001: Mechanisms of intense Alpine rainfall. J. Atmos. Sci., 58, 1732-1749.

Rudari, R., D. Entekhabi, and G. Roth, 2005: Large-scale atmospheric patterns associated with mesoscale features leading to extreme precipitation events in northwestern Italy. $A d v . W a-$ ter Resour., 28, 601-614.

Schär, C., and H. C. Davies, 1988: Quasi-geostrophic stratified flow over isolated finite amplitude topography. Dyn. Atmos. Oceans, 11, 287-306.

Smith, R. B., 1989: Mountain-induced stagnation points in hydrostatic flow. Tellus, 41A, 270-274.

Steppeler, J., G. Doms, U. Schattler, H. W. Bitzer, A. Gassmann, U. Damrath, and G. Gregoric, 2003: Meso-gamma scale forecasts using the nonhydrostatic model LM. Meteor. Atmos. Phys., 82, 75-96.

Temperton, C., 1988: Implicit normal mode initialization. Mon. Wea. Rev., 116, 1013-1031.

_ , and M. Roch, 1991: Implicit normal mode initialization for an operational regional model. Mon. Wea. Rev., 119, $667-677$.

Tiedtke, M., 1989: A comprehensive mass flux scheme for cumulus parameterization in large-scale models. Mon. Wea. Rev., 117, 1779-1800.

Turato, B., O. Reale, and F. Siccardi, 2004: Water vapor sources of the October 2000 Piedmont flood. J. Hydrometeor., 5, 693-712.

Uppala, S. M., and Coauthors, 2005: The ERA-40 Re-Analysis. Quart. J. Roy. Meteor. Soc., 131, 2961-3012.

Vidale, P. L., D. Lüthi, C. Frei, S. Seneviratne, and C. Schär, 2003: Predictability and uncertainty in a regional climate model. J. Geophys. Res., 108, 4586, doi:10.1029/2002JD002810. 